\title{
Severe Community-Acquired Pneumonia
}

\author{
Wendy I. Sligl, MD, MSC, FRCPC ${ }^{a} *$, Thomas J. Marrie, MD, FRCPC, MACP
}

\section{KEYWORDS}

- Community-acquired pneumonia $\bullet$ Respiratory failure $\bullet$ Lung $\bullet$ Pulmonary sepsis

- Intensive care

\section{KEY POINTS}

- Approximately $10 \%$ to $20 \%$ of all adult patients hospitalized with community-acquired pneumonia (CAP) require admission to an intensive care unit (ICU).

- Of CAP patients admitted to the ICU, $40-80 \%$ require mechanical ventilation and up to $50 \%$ present with concomitant septic shock.

- Typical and atypical causative microorganisms responsible for CAP are predictable based on patient risk factors.

- Various scoring systems (such as the Pneumonia Severity Index) are available to help define CAP severity, prognosis, and optimal site of care.

- Diagnosis of severe CAP is based on clinical features plus comprehensive radiographic, laboratory, and microbiologic testing.

- Empiric antimicrobial therapy should be initiated as quickly as possible, with adherence to Infectious Diseases Society of America and American Thoracic Society guidelines.

- Targeted antimicrobial therapy should be prescribed once a microbial cause is identified.

- Source control, adjunctive therapies, and assisted organ support should be included in the care of the critically ill CAP patient.

- Common complications suffered by patients with severe CAP include empyema, lung abscess, pneumothorax, acute respiratory distress syndrome, chronic respiratory failure requiring tracheostomy, cardiac complications, and multisystem organ failure.

- Prevention strategies include smoking cessation, immunization, and infection control measures.

\section{BACKGROUND}

Community-acquired pneumonia (CAP) is a common and serious condition. Combined with influenza, pneumonia is the most frequent cause of infection-related death and the eighth leading cause of death overall in the United States. ${ }^{1,2}$ CAP occurs in

\footnotetext{
a Division of Infectious Diseases and Critical Care Medicine, University of Alberta, 3C1.12 WMC 8440112 Street, Edmonton, Alberta T6G 2B7, Canada; b Dalhousie University, Halifax, Nova Scotia B3H 4R2, Canada

* Corresponding author.

E-mail address: wsligl@ualberta.ca
} 
approximately 4 million adults in the United States, accounting for 10 million physician visits, 1.1 million hospitalizations, and 50,000 deaths per year. ${ }^{3-5}$

As many as $20 \%$ to $60 \%$ of CAP patients require hospital admission due to disease severity, decompensation of underlying comorbid disease, or social reasons. ${ }^{6-10}$ Of those, $10 \%$ to $22 \%$ have severe pneumonia requiring critical care. ${ }^{11-14}$ Morbidity and mortality in patients with severe CAP remain high, despite advances in antimicrobial therapy and critical care. Of those admitted to the ICU, $44 \%$ to $83 \%$ of patients require mechanical ventilation at the time of admission ${ }^{14-19}$ and up to $50 \%$ present with concomitant septic shock. ${ }^{20}$ Mortality rates are high, ranging from $11 \%$ to $56 \% .^{11,21-26}$

\section{EPIDEMIOLOGY}

Although the definition of severe pneumonia remains somewhat subjective and imprecise de facto respiratory and/or circulatory failure often define this entity. Various CAP scoring systems have been devised and validated in an attempt to aid the clinician regarding treatment, prognosis, and site of care. Although most scoring systems sensibly reflect disease severity, all continue to present challenges and inadequacies. Differences in methods of derivation, including differences in intensive care unit (ICU) reference populations and admission criteria, confounding variables (such as treatment restrictions or limitations in the elderly), model variables included, and variations in time course of pneumonia severity result in inconsistent performance of these tools. ${ }^{6}$

The most widely cited definition of severe CAP however, and the one we will use, is presented in the Joint Guidelines of the Infectious Diseases Society of America (IDSA) and American Thoracic Society (ATS) (Box 1). ${ }^{27}$ Major criteria for severe CAP include either concomitant septic shock or the need for mechanical ventilation. Minor criteria include 3 or more of the following: respiratory rate greater than or equal to 30 breaths/ min, $\mathrm{PaO}_{2} / \mathrm{FiO}_{2}$ ratio less than or equal to 250 , multilobar infiltrates, blood urea nitrogen greater than or equal to $20 \mathrm{mg} / \mathrm{dL}$, leukopenia (white blood cell [WBC] count $<4000$ cells $/ \mathrm{mm}^{3}$ ), thrombocytopenia (platelet count $<100,000$ cells $/ \mathrm{mm}^{3}$ ), hypothermia (core temperature $<36^{\circ} \mathrm{C}$ ), or hypotension requiring aggressive fluid resuscitation. These characteristics are also suggested by the IDSAVATS as ICU admission criteria.

Of course, not all patients meeting these criteria are admitted to ICUs. This decision may depend on numerous factors, including local policies, patient wishes, and resource availability (including the availability of intermediate care units). For example, hospitalization rates for influenza and pneumonia among adults older than 65 years vary considerably by geographic region in Canada. Data from the Canadian Institute for Health Information from 1996 to 1998 demonstrate rates that were highest in the Northwest Territories (4253 per 100,000) compared with the lowest rates in Quebec $(1185$ per 100,000$)$ and an overall national average of 1358 per $100,000 .^{28}$

In addition, rates of CAP vary by season, with more cases occurring in the winter months when influenza infection is more prevalent. ${ }^{29}$ Rates of pneumonia are higher for men than for women and for blacks compared with Caucasians, presumably related to various genetic polymorphisms and/or socioeconomic factors that are not well understood. Lastly, CAP incidence increases significantly with age due to immunosenescence, and given the aging population, is expected to steadily increase over the next few decades. ${ }^{16}$

\section{WHY DOES SEVERE PNEUMONIA DEVELOP IN OTHERWISE HEALTHY PERSONS?}

In a prospective study of all adults with pneumonia presenting to the Emergency Departments of hospitals in Edmonton, Canada, $5 \%$ were admitted to an ICU. ${ }^{30} \mathrm{~A}$ much 
Box 1

IDSA/ATS criteria for severe CAP

Minor criteria ${ }^{a}$

Respiratory rate ${ }^{\mathrm{b}} \geq 30$ breaths $/ \mathrm{min}$

$\mathrm{PaO}_{2} / \mathrm{FiO}_{2}$ ratio ${ }^{\mathrm{b}} \leq 250$

Multilobar infiltrates

Confusion/disorientation

Uremia (BUN level $\geq 20 \mathrm{mg} / \mathrm{dL}$ )

Leukopeniac (WBC count $<4000$ cells $/ \mathrm{mm}^{3}$ )

Thrombocytopenia (platelet count $<100,000$ cells $/ \mathrm{mm}^{3}$ )

Hypothermia (core temperature $<36^{\circ} \mathrm{C}$ )

Hypotension requiring aggressive fluid resuscitation

Major criteria

Invasive mechanical ventilation

Septic shock with the need for vasopressors

Abbreviations: $\mathrm{BUN}$, blood urea nitrogen; $\mathrm{FiO}_{2}$, fraction of inspired oxygen; $\mathrm{PaO}_{2}$, arterial partial pressure of oxygen.

a Other criteria to consider include hypoglycemia (in nondiabetic patients), acute alcoholism/ alcoholic withdrawal, hyponatremia, unexplained metabolic acidosis or elevated lactate level, cirrhosis, and asplenia.

${ }^{b}$ A need for invasive ventilation can be substituted for a respiratory rate greater than or equal to 30 breaths/min or $\mathrm{PaO}_{2} / \mathrm{FiO}_{2}$ less than or equal to 250 .

${ }^{\mathrm{C}}$ As a result of infection alone.

higher percentage of younger patients were admitted to the ICU compared with older patients. For example, $18 \%$ to $36 \%$ of 17 to 19 -year-olds were admitted to the ICU, $12 \%$ to $18 \%$ of 20 to $34-y e a r-o l d s$, and after 59 years of age the percentage markedly declined. ${ }^{30}$

\section{Infecting Microorganism Load (Burden)}

In an investigation of the role of infected parturient cats in the transmission of Coxiella burnetii in Maritime Canada, we found an incubation period of 4 to 27 days. ${ }^{31}$ Shorter incubation periods were associated with exposure to products of conception, indicating a dose-response effect. ${ }^{31}$ Similarly, Albrich and colleagues ${ }^{32}$ demonstrated $^{2}$ in 514 adults in South Africa, 58\% of whom were affected by human immunodeficiency virus (HIV), that microorganism load was associated with the development of pneumonia. Specifically, more than or equal to 8000 copies $/ \mathrm{mL}$ of the lytA gene detected by real-time polymerase chain reaction (PCR) and greater than or equal to $15,000 \mathrm{cfu} / \mathrm{mL}$ of Streptococcus pneumoniae by quantitative culture in nasopharyngeal swabs were associated with the development of pneumococcal pneumonia. Werno and colleagues ${ }^{33}$ likewise found that in patients with pneumonia, bacterial load as measured by quantitative lytA PCR on sputum, serum, and urine showed increasing severity of pneumonia with increasing bacterial load. An association between high bacterial load and the subsequent development of septic shock in patients with community-acquired pneumonia has also been described. ${ }^{34}$ 


\section{Virulence of the Infecting Microorganism}

The USA 300 strain of methicillin-resistant Staphylococcus aureus exemplifies the concept of increased virulence. It has several virulence genes, including luk-S-PV/ lukF-PV and arcA, coding for Paton-Valentine leukocidin and the arginine catabolic mobile element, respectively. ${ }^{35}$ This strain has successfully spread from the United States to 36 countries on 5 continents. ${ }^{35}$ This strain often causes severe, necrotizing pneumonia. A recent publication describing 31 patients with methicillin-sensitive $S$. aureus CAP due to a Panton-Valentine leukocidin secreting strain illustrated how lethal this infection can be, affecting mainly healthy children and young adults. ${ }^{36}$ Thirteen of the 31 patients (32\%) died, most (93\%) had multilobar pneumonia and $21(68 \%)$ required mechanical ventilation. The mean age of those who died was 26 years.

Up to the year 2000, there were 11 cases of Pseudomonas aeruginosa causing pneumonia in otherwise healthy young adults. ${ }^{37}$ The mortality rate was $33 \%$, and there was an association with exposure to aerosols of contaminated water. ${ }^{37}$ In one study, an isolate from such a patient was not more virulent in a mouse model than other $P$. aeruginosa isolates. ${ }^{38}$

Legionnaires' disease should be considered in young adults with severe pneumonia. The outbreak that gave this disease its name and led to the isolation of the causative microorganism was associated with the 58th Annual Convention of the American Legion held in Philadelphia from July 21 to 24, 1976. One hundred eightytwo of the attendees developed pneumonia. One hundred forty-seven (81\%) were hospitalized and 29 (16\%) died. ${ }^{39}$ The same evolutionary strategies that allow Legionella to survive in amoebae allow it to survive in human alveolar macrophages. ${ }^{40}$

In some instances, such as in the case of Hantavirus, target cell infection may result in severe pneumonia. ${ }^{41}$ Hantavirus infects endothelial cells via a nonlytic mechanism, disrupting endothelial integrity, resulting in low pressure pulmonary edema manifested as severe pneumonia. ${ }^{41}$

Lastly, severe acute respiratory syndrome (SARS) coronavirus, the coronavirus responsible for SARS, which caused 8096 cases of pneumonia starting in November 2002 and resulted in 774 (9.6\%) deaths, is an agent that causes severe pneumonia in otherwise healthy individuals as well as in others. ${ }^{42}$ This bat virus uses angiotensinconverting enzyme 2 as a receptor to enter the host cell and trigger massive enzymatic cleavage, resulting in severe physiologic derangements that manifest as severe pneumonia. ${ }^{43}$

\section{Host Factors}

In addition to bacterial burden and virulence, there may be subtle impairments of the immune response that contribute to the severity of pneumonia. For example, low concentrations of both immunoglobulin G (IgG) 1 and IgG-2 were found in patients with noninfluenza severe CAP, and low concentrations of IgG-2 were found in those with pneumonia due to influenza virus $A(\mathrm{H} 1 \mathrm{~N} 1 / 09) .{ }^{44}$ Mannose-binding lectin function was lower in those with Legionnaires' disease than in age-matched and sexmatched uninfected controls. ${ }^{45}$ Homozygosity for the FCGR2A-H131 receptor predisposes to severe bacteremic pneumococcal pneumonia. ${ }^{46}$ The leukocyte receptor for the Fc portion of IgG plays a key role in the response to pathogens such as S. pneumoniae in mediating phagocytosis, respiratory burst, cytokine production, antigen presentation, and regulation of antibody response. ${ }^{46}$

During the spring of 2009, a novel H1N1 influenza virus (H1N1/09) of swine origin caused human infection, resulting in an estimated 59 million illnesses, 265,000 
hospitalizations, and 12,000 deaths in the United States as of mid-February $2010 .{ }^{47}$ Although the overall case fatality rate was low, approximately $9 \%$ to $31 \%$ of hospitalized patients were admitted to an ICU and $14 \%$ to $46 \%$ of these patients died. ${ }^{47}$ Although pregnant women represent only $1 \%$ to $2 \%$ of the population, among patients with $\mathrm{H} 1 \mathrm{~N} 1 / 09$ virus infection they accounted for $7 \%$ to $10 \%$ of hospitalized patients, $69 \%$ of ICU patients, and $6 \%$ to $10 \%$ of patients who died. ${ }^{47}$ The interferon inducible transmembrane protein family members (IFITM) play a role in restricting the replication of multiple pathogenic viruses. ${ }^{48}$ Patients who were hospitalized with pandemic influenza H1N1/09 were more likely to have a minor IFITM3 allele that alters a splice acceptor site, resulting in reduced ability to restrict influenza in vitro. ${ }^{48}$

These examples illustrate how severe pneumonia in otherwise healthy persons is likely to be due to a combination of pathogen dose/burden and virulence as well as subtle impairments of host defenses.

\section{PATHOGENESIS}

Despite constant exposure to particulate material and microorganisms via microaspiration, the lower respiratory tract remains sterile because of innate and acquired pulmonary defense mechanisms. The development of CAP indicates a defect in host defense, exposure to a particularly virulent microorganism, an overwhelming inoculum of microorgnanisms, or a combination of these factors as previously discussed. ${ }^{49,50}$

Various virulence factors enable microflora to establish infection. For example, Chlamydophila pneumoniae produces a ciliostatic factor, ${ }^{51}$ Mycoplasma pneumoniae can shear respiratory cilia, ${ }^{52}$ influenza viruses reduce tracheal mucous velocity, and S. pneumoniae has a polysaccharide capsule that inhibits phagocytosis. ${ }^{53}$ Other microorganisms are innately more resistant to immune defenses, for example, mycobacterial species, Nocardia, and Legionella are resistant to the microbicidal activity of phagocytes. $^{54}$

In addition to pathogen characteristics, host characteristics are important in predicting risk of infection (Box 2). Several predisposing host conditions have been described in CAP. These include alterations in level of consciousness, tobacco smoking, alcohol consumption, hypoxemia, acidosis, toxic inhalation, pulmonary edema, uremia, malnutrition, immune suppression (as a result of solid organ or hematopoietic stem cell transplant, chemotherapy, chronic glucocorticoid use, biologic therapies, or infection with HIV), advanced age, structural lung disease (cystic fibrosis, bronchiectasis, chronic obstructive pulmonary disease (COPD), previous pneumonia, or chronic bronchitis), ciliary dysfunction (immotile cilia syndrome, Kartagener syndrome), Young syndrome (also known as sinusitis-infertility syndrome and Barry-Perkins-Young syndrome, a rare condition presenting as bronchiectasis, rhinosinusitis, and infertility due to abnormally viscous mucus), dysphagia, viral respiratory infection, lung malignancy, and bronchial obstruction (due to stenosis, tumor, or foreign body). ${ }^{55}$

An increase in the incidence of CAP due to increased gastric $\mathrm{pH}$ has been well documented with the ubiquitous use of $\mathrm{H} 2$ blockers, proton pump inhibitors, and antacids. ${ }^{56-58}$ Other medications such as antipsychotics ${ }^{59,60}$ and inhaled glucocorticoids $^{61}$ have been associated with an increased risk of CAP.

\section{MICROBIAL CAUSE}

There are over a hundred microorganisms, including bacteria, viruses, fungi, and parasites, that can cause CAP. However, most cases of pneumonia are caused by a handful of pathogens, varying in distribution by geography and clinical setting. 


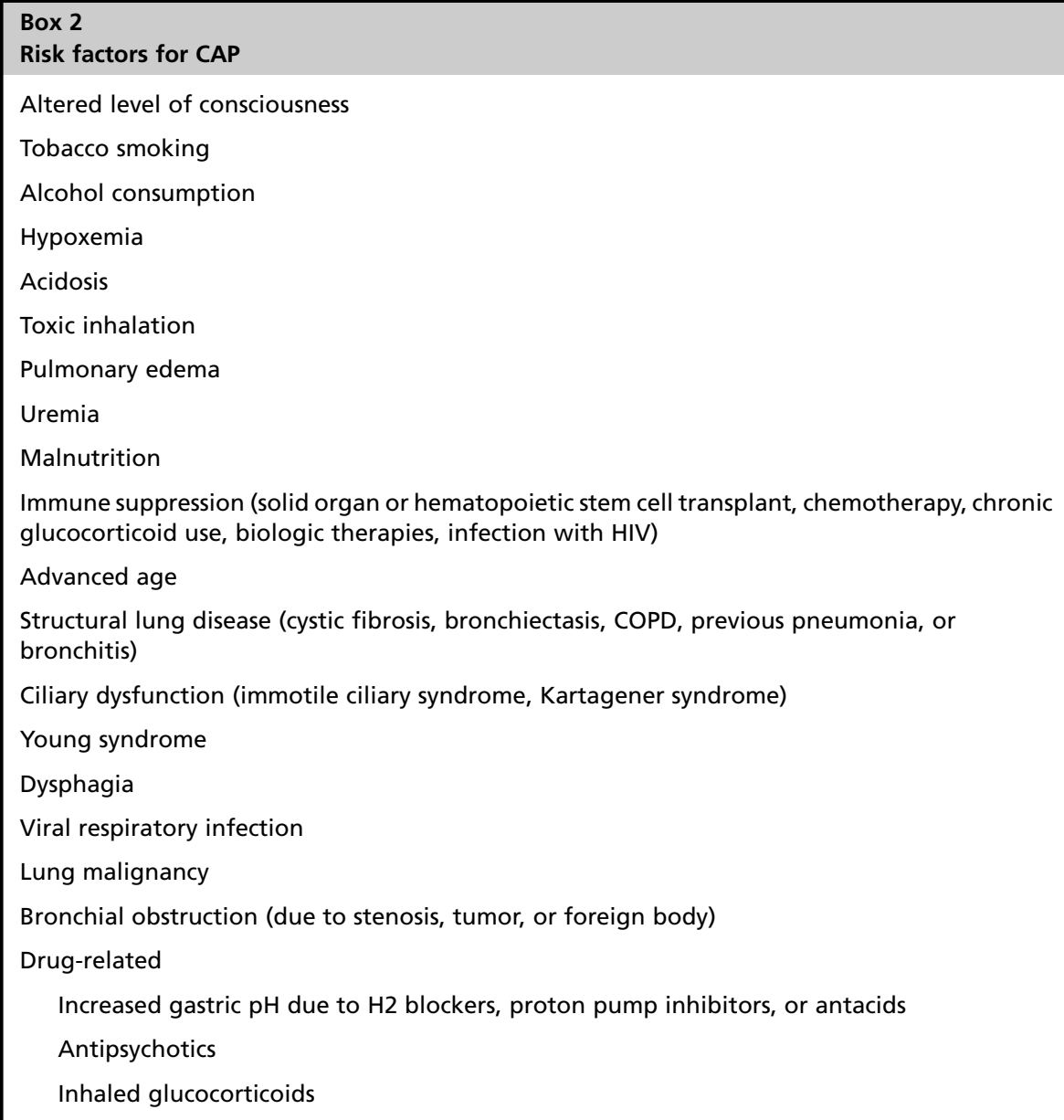

\section{Usual Pathogens}

Causes of bacterial CAP have traditionally been classified into 2 groups: typical and atypical pathogens. Typical microorganisms include S. pneumoniae, Haemophilus influenzae, group A streptococcus, Moraxella catarrhalis, Staphylococcus aureus, anaerobes, and aerobic gram-negative enteric bacilli. Atypical pathogens include Legionella spp., Mycoplasma pneumoniae, Chlamydophila (formerly Chlamydia) pneumoniae, and Chlamydophila psittaci. There are no specific findings from history, physical examination, or routine laboratory/imaging tests that allow clinicians to distinguish between typical and atypical pathogens. ${ }^{62}$

The most common pathogens in patients with severe CAP (Box 3) include S. pneumoniae, Haemophilus influenzae, Staphylococcus aureus, gram-negative enteric bacilli, and occasionally $P$. aeruginosa. ${ }^{63,64} \mathrm{~S}$. pneumoniae is the most frequently isolated pathogen ${ }^{15,19,26,65-67}$ whereas $S$. aureus, gram-negative enterics, and $P$. aeruginosa tend to be associated with specific patient subtypes. For example, $S$. aureus pneumonia is common following influenza infection, ${ }^{68-70}$ whereas $P$. aeruginosa infection is more prevalent in patients previously exposed to antimicrobials, with structural 
Box 3

Common microbial causes of severe CAP

Streptococcus pneumoniae

Haemophilus influenzae

Moraxella catarrhalis

Staphylococcus aureus

Legionella spp.

Enterobacteriaceae (eg, Escherichia coli, Klebsiella and Enterobacter spp.)

Pseudomonas aeruginosa ${ }^{a}$

Viruses (influenza, parainfluenza, RSV, coronaviruses, HMPV, adenovirus)

Fungi

Abbreviations: HMPV, human metapneumovirus; RSV, respiratory syncytial virus.

${ }^{a}$ In select populations: patients previously exposed to antimicrobials, those with structural lung disease, or those treated chronically with corticosteroids.

lung disease (such as cystic fibrosis or bronchiectasis), or chronically treated with corticosteroids (>10 mg/d prednisone or equivalent). ${ }^{71}$

Atypical pathogens, such as Mycoplasma pneumoniae and Chlamydophila species, are less commonly isolated in patients with severe CAP; however, this may reflect the lack of rapid, specific, and standardized testing for their detection. The frequency of Legionella, as well as other less common causes such as Mycobacterium tuberculosis, Coxiella burnetii (Q fever), Francisella tularensis (tularemia), and endemic fungi (such as histoplasma, coccidioides, blastomyces) varies with epidemiologic exposure. Respiratory virus infection, in particular influenza $A$, can result in severe pneumonitis with or without secondary bacterial pneumonia.

Despite routine microbiological testing in most patients with severe CAP, a microbial diagnosis is confirmed in half of patients at best. ${ }^{63,64,72,73}$

\section{Drug-resistant S. Pneumoniae}

Penicillin resistance in S. pneumoniae was first described in 1977 in South Africa. ${ }^{74}$ Since then, resistance of pneumococci to a variety of antimicrobial agents, including beta-lactams, macrolides, tetracyclines, folate inhibitors, and fluoroquinolones, has evolved worldwide.

Rates of penicillin resistance vary by geographic region, with higher rates in the Asia-Pacific region compared with the United States or Canada. ${ }^{75}$ Our understanding of the impact of penicillin resistance on pneumonia outcomes has been complicated by recent changes in susceptibility breakpoints. In 2008, penicillin minimum inhibitory concentration (MIC) breakpoints were increased substantially for nonmeningeal pneumococcal infections, placing much fewer organisms in the intermediate or resistant categories. Before this change, a disproportionately high number of clinical isolates were considered penicillin intermediate or resistant. With current definitions, however, approximately $85 \%$ of pneumococci are fully susceptible to penicillin. ${ }^{76}$ Earlier studies have been unable to demonstrate an association between beta-lactam resistance and poor outcomes and instead suggest factors such as age, underlying disease, and severity of illness are greater predictors of mortality. ${ }^{77-81}$

Macrolide resistance is also becoming increasingly prevalent worldwide, with up to $30 \%$ of isolates demonstrating resistance in the United States. ${ }^{82}$ Most of the 
resistance in the United States, however, is low-level, efflux-mediated (vs resistance due to an altered ribosomal target site as seen more commonly in Europe), and has not been associated with poor outcomes. ${ }^{83,84}$

Respiratory fluoroquinolone resistance remains low, with surveillance studies suggesting less than $1 \%$ resistance in North America. ${ }^{85,86}$ The major risk factor for the acquisition of resistance is recent antibiotic exposure, prompting the recommendation to avoid agents prescribed in the prior 3 months, where possible. ${ }^{87}$

\section{Community-Acquired Methicillin-resistant Staphylococcus aureus}

Methicillin-resistant Staphylococcus aureus (MRSA) was first described in $1961 .{ }^{88,89}$ Having since spread worldwide, MRSA is a common cause of both nosocomial and community-acquired infections. The prevalence of methicillin-resistance among $S$. aureus isolates varies by patient population, geography, and health care setting, with high prevalence $(\sim 60 \%)$ in ICUs in the United States. ${ }^{90}$ Methicillin-resistance is mediated by penicillin-binding protein (PBP) $2 a$, an altered binding protein encoded by the mecA gene. The mecA gene is located on a mobile genetic element called the staphylococcal chromosome cassette (SCCmec).

Community-acquired methicillin-resistant Staphylococcus aureus (CA-MRSA) has recently emerged as a cause of severe necrotizing CAP. Although generally more virulent compared with hospital-acquired (HA-MRSA) strains, ${ }^{91}$ CA-MRSA tends to be more susceptible to non-beta-lactam antibiotics (such as clindamycin, tetracyclines, and trimethoprim/sulfamethoxazole) as a result of a shorter SCCmec mobile element (types IV and V) that is less able to carry additional resistance genes. Specific CA-MRSA strains (eg, USA300) have been associated with the production of the Panton-Valentine leukocidin (PVL) toxin, ${ }^{92-94}$ which lyses neutrophils, often resulting in necrotizing pneumonia, lung abscess, or empyema. ${ }^{68,95}$ Various reports of the USA300 strain causing severe, rapidly progressive, necrotizing pneumonia (mainly in otherwise healthy children and young adults) with high associated mortality have been well documented. ${ }^{69,95-99}$ In a systematic review of 114 patients, the estimated incidence of MRSA CAP was 0.5 to 0.6 cases per 100,000 . Seventy-five (69\%) out of 109 patients were younger than 35 years, influenza-like symptoms were present in $41 \%$ of patients, and the majority $(75 \%)$ had multilobar consolidation or bilateral lung infiltrates. Most patients $(77 \%)$ required ICU care, with prolonged (19 days) lengths of stay and high (45\%) mortality. ${ }^{97}$

Risk factors for CA-MRSA include skin trauma, contact sport participation, injection drug use, men who have sex with men, crowded living conditions, recent incarceration, and prior/known MRSA colonization. CA-MRSA pneumonia should also be suspected in young, otherwise healthy patients with a history of an influenza-like illness who present with severe pneumonia.

\section{Influenza and Other Viral Pathogens}

Seasonal influenza occurs almost exclusively during the winter months and results in major morbidity, mortality, and cost. In fact, seasonal influenza has been estimated to result in more than 3 million hospital days, 31 million outpatient visits, and $\$ 10$ billion in medical costs annually in the United States. ${ }^{100}$ Of patients admitted to hospital with influenza infection, it is mainly the elderly and those with severe comorbid disease that require ICU admission.

In addition to the major impact caused by seasonal influenza, the threat of pandemic influenza is ever-present. The recent influenza A H1N1/09 pandemic served to remind us of this looming danger. This genetic reassortment virus (swine, avian, and human) was first identified in March 2009, spreading from the Southwestern United States and 
Mexico worldwide, resulting in more than 4000 deaths. Young patients were disproportionally affected, presumably due to cross-immunity in elderly patients from exposure to similar influenza strains that circulated before 1957.

In a study using mathematical modeling to approximate the impact of pandemic disease, the Centers for Disease Control and Prevention estimated 12,470 fatal cases occurred in the United States between April 2009 and April 2010. ${ }^{101}$ In Australia, approximately $5 \%$ of the population developed H1N1/09-related illness, $0.3 \%$ of infected patients were hospitalized, but a disproportionate percentage (20\%) of hospitalized patients required ICU care. ${ }^{102}$

Among 168 critically ill Canadian patients with $\mathrm{H} 1 \mathrm{~N} 1 / 09$, the mean age was low (32 years). ${ }^{103}$ Common pre-existing comorbidities were chronic lung disease $(41 \%)$ and obesity (33\%), and Aboriginal Canadians were overrepresented (26\%). Most patients developed diffuse, rapidly progressive, bilateral pneumonitis and more than $80 \%$ required mechanical ventilation. Secondary bacterial pneumonia was diagnosed in $24 \%$ of cases, most commonly due to $S$. aureus and S. pneumoniae. Overall mortality was high (17\%) at 90 days.

Highly pathogenic avian H5N1 influenza viruses are endemic among bird and poultry populations in Asian countries. ${ }^{104,105}$ The first report of clinical disease in humans was in Hong Kong in 1997 when 18 cases occurred during a poultry outbreak in live-bird markets. ${ }^{106,107}$ This outbreak was associated with high mortality (33\%) and a high incidence of pneumonia at $61 \%$, and about half $(51 \%)$ of the cases required intensive care treatment. Although only sporadic transmission of avian influenza viruses to humans is documented, the emergence of a pandemic strain is possible.

In addition to influenza, other respiratory viruses have potential for epidemic spread. The SARS outbreak was a good example. Beginning in February 2003, approximately 300 cases of severe, rapidly progressive respiratory disease were reported in the Guangdong Province of China. This novel SARS coronavirus subsequently spread worldwide, with large numbers of cases reported from Hong Kong, Vietnam, Singapore, and Canada. With a total of more than 8000 cases, 774 deaths, and a case-fatality rate of up to $12 \%$, the morbidity and mortality from this epidemic was significant. Most patients affected by SARS required critical care for severe hypoxia or acute respiratory distress syndrome (ARDS).

More, a novel beta coronavirus causing disease in nine patients ${ }^{108,109}$ and associated with high mortality $(56 \%)$ has been reported. ${ }^{110}$ So although SARS is no longer a threat, other pathogens remain a threat, awaiting their "chance in the sun."

\section{DIAGNOSIS}

CAP is defined as an acute infection of the lung parenchyma acquired in the community (ie, in patients not hospitalized or resident in long-term care facilities for $>2$ weeks before symptom onset). ${ }^{111}$ CAP is distinguished from other subtypes of pneumonia including hospital-acquired pneumonia or health care associated pneumonia, which is important epidemiologically because these subtypes differ in microbiology, empiric therapy, and outcomes.

The diagnostic approach to severe CAP includes clinical criteria, radiographic evaluation, and diagnostic testing for microbial cause.

\section{Clinical Criteria}

Common clinical symptoms of severe CAP include cough (41\%), fever (28\%), dyspnea, pleuritic chest pain (5\%), and sputum production (30\%). ${ }^{65}$ Purulent sputum production is most common in bacterial pneumonia. Specific descriptions of sputum 
color or consistency (eg, rust-colored sputum with S. pneumoniae or red current jelly sputum with Klebsiella infection) have not proved to be helpful in distinguishing microbial cause. Patients may also present with mental status changes $(32 \%)^{65}$ or gastrointestinal symptoms (nausea, vomiting, or diarrhea).

Physical examination signs commonly include fever (although this is less reliable in elderly patients), tachypnea, and tachycardia. ${ }^{112}$ Patients with overwhelming sepsis or underlying comorbid disease (such as end-stage liver disease or malnutrition) may present with hypothermia instead of fever. Bronchial breath sounds or egophony may be present on auscultation. However, no individual or combined clinical findings have been found to accurately predict whether or not a patient has pneumonia. ${ }^{112}$ In severe CAP, patients with severe hypoxia $\left(\mathrm{PaO}_{2}<55 \mathrm{~mm} \mathrm{Hg}\right.$ despite supplemental oxygen) or hypercapnia $\left(\mathrm{PaCO}_{2}\right.$ rise of $>10 \mathrm{~mm} \mathrm{Hg}$ with respiratory acidosis) generally require intubation and mechanical ventilation. Although objective measures have been suggested, the decision to initiate mechanical ventilation should be based on a global clinical assessment. Patients with CAP and septic shock present with hypotension (systolic blood pressure $<90 \mathrm{~mm} \mathrm{Hg}$ ) that is unresponsive to fluid resuscitation and require vasopressor support.

On laboratory investigation, leukocytosis is most common with a left shift of immature cells. Leukopenia can also occur, in particular in critically ill patients with overwhelming sepsis. These patients commonly present with concomitant multiorgan dysfunction, such as acute kidney injury (AKI), hepatic dysfunction, disseminated intravascular coagulation, lactic acidosis, and encephalopathy.

\section{Biologic Markers}

C-reactive protein (CRP) and procalcitonin (PCT) have been used, with varying success, to help distinguish between bacterial and nonbacterial pneumonia.

CRP is an acute-phase reactant produced predominantly by hepatocytes in response to cytokines such as interleukin- 6 and tumor necrosis factor. ${ }^{113,114}$ It is neither sensitive nor specific for infection; however, markedly elevated CRP levels have been strongly associated with infection. Infection was found in approximately $80 \%$ of patients with levels greater than $100 \mathrm{mg} / \mathrm{L}$ and in $88 \%$ of patients with values greater than $500 \mathrm{mg} / \mathrm{L} .{ }^{115,116}$ In other studies, CRP levels greater than $40 \mathrm{mg} / \mathrm{L}$ were associated with a sensitivity of $70 \%$ to $73 \%$ and specificity of $65 \%$ to $90 \%$ for bacterial pneumonia. ${ }^{117,118}$ CRP may also be elevated in patients with viral infections, although often not to the same extent as in bacterial infection. ${ }^{119-121}$

In addition, CRP levels may be correlated with disease severity; a study in CAP patients demonstrated that median CRP levels were higher in hospitalized patients compared with ambulatory patients. ${ }^{119}$ Data on CRP testing exclusively in patients with severe CAP are lacking. Given its poor specificity in hospitalized patients, the use of CRP testing as an adjunct in the diagnosis of bacterial infection remains of minimal benefit.

PCT is a precursor of calcitonin that is released in response to microbial toxins (such as lipopolysaccharide in gram-negative infections) and host inflammatory mediators (such as interleukin-1, tumor necrosis factor, and interleukin-6), resulting in high serum levels in active bacterial infections. PCT appears to be more sensitive than CRP for the detection of bacterial pneumonia. ${ }^{122}$ Previous studies have suggested a PCT level less than $0.1 \mathrm{mcg} / \mathrm{L}$ should discourage the use of antibacterial therapy, whereas levels greater than $0.25 \mathrm{mcg} / \mathrm{L}$ should suggest such therapy. ${ }^{123,124}$ Studies have demonstrated lower rates of antibiotic exposure when PCT testing is used ${ }^{125}$ and, in addition, that levels correlate with disease severity, ${ }^{122,126}$ mortality, ${ }^{122}$ and bacteremia. $^{127}$ 
Clinically, the measurement of PCT may help to distinguish between bacterial and viral pneumonia, predict severity and outcomes, and reduce antimicrobial use. Discontinuation strategies based on PCT testing led to a reduction in duration of therapy and increased 28-day antibiotic-free days without negatively affecting other outcomes. $^{128}$

\section{Radiographic Criteria}

The presence of opacity on plain chest radiography is the gold standard for radiographic diagnosis of pneumonia. Plain films are widely available in virtually all hospital settings, minimally invasive, and inexpensive and should be obtained in all critically ill patients suspected to have pneumonia. ${ }^{27}$ Radiographic findings of CAP include lobar or multilobar consolidation (Fig. 1), interstitial infiltration, and cavitation. Posteroanterior and lateral radiographs are preferred but this is rarely possible in critically ill patients; portable anteroposterior (AP) films are therefore more commonly obtained but undoubtedly of lower quality.

Given the suboptimal quality of portable AP films as well as substantial differences in individual interpretation of plain radiographs among emergency physicians, intensivists, and even radiologists, computed tomography (CT) scanning is commonly pursued in critically ill patients (Fig. 2), in particular when specific disease complications, such as empyema or lung abscess, are suspected. The level of radiation exposure from CT scanning varies due to technical factors but is generally high. Successfully reducing radiation dose while maintaining diagnostic accuracy is important, specifically in pediatric populations. ${ }^{129}$

\section{Microbial Cause}

Given the low likelihood of identification of a microbial pathogen, most patients with severe CAP are treated empirically. Despite this, all efforts to increase pathogen detection via appropriate testing should be used, because pathogen-directed therapy is associated with substantial benefits including the avoidance of unnecessary

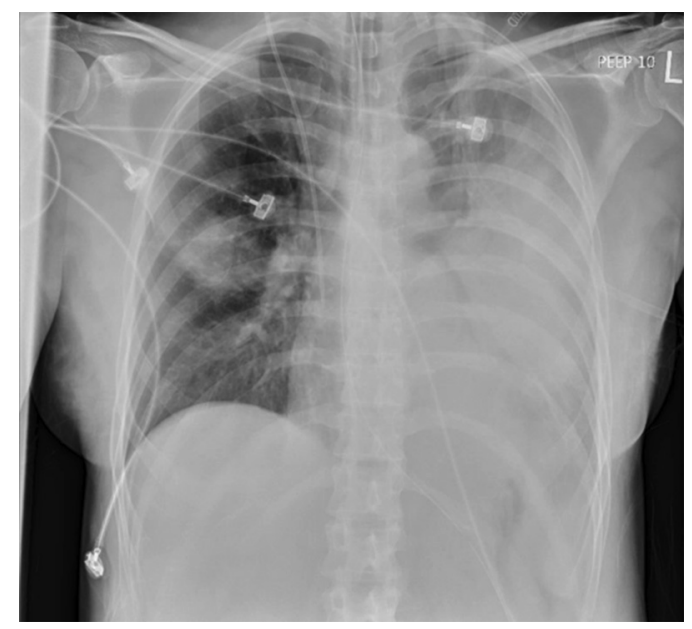

Fig. 1. Severe pneumonia in an intubated and mechanically ventilated critically ill patient. Radiograph demonstrates extensive dense left lung consolidation (with air bronchograms) and less-prominent focal right midlung consolidation. Support lines and tubes are well positioned (endotracheal tube, gastric feeding tube, right internal jugular central venous catheter). 


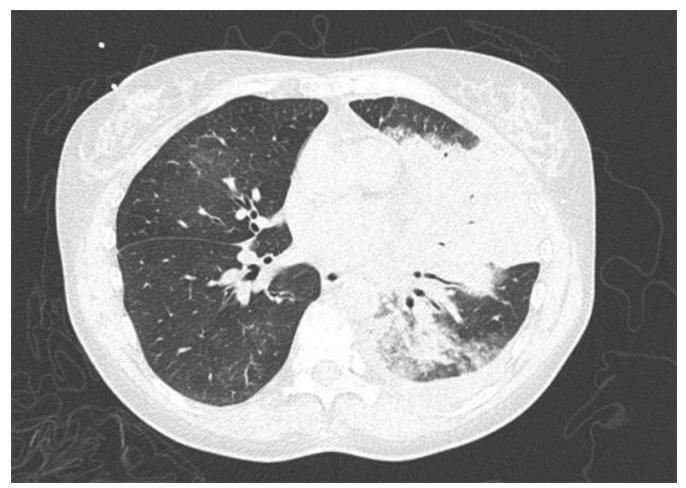

Fig. 2. Noncontrast helical CT imaging of the upper chest showing extensive pneumonic consolidation involving nearly the entire lingula and superior segment of left lower lobe.

adverse events, reduction of antimicrobial resistance, and potential cost minimization by using narrower spectrum agents.

For these reasons, the 2007 IDSA/ATS consensus guidelines recommend diagnostic testing for microbial cause in all patients with severe CAP, ${ }^{27}$ which includes pretreatment blood cultures, urinary antigen testing for $S$. pneumoniae and Legionella (where available), and sputum culture (expectorated, endotracheal, or bronchoscopic specimens). Although pretreatment cultures are optimal, empiric therapy should not be significantly deferred in critically ill patients for the purpose of specimen acquisition.

Pretreatment blood cultures are positive in $9 \%$ to $27 \%$ of ICU patients with CAP. ${ }^{15,18,19,26,66,67}$ The major disadvantage to blood culture acquisition in ICU patients, in particular with vascular catheters in situ, is the high rate of false positivity due to skin contaminants (such as coagulase-negative staphylococcus), which can be as high as $10 \% .^{130}$

Expectorated sputum is indicated in unintubated patients with severe CAP; however, results must be interpreted in the context of specimen quality. Numerous strategies have been proposed for quality evaluation; our institution uses a quality score, which denotes a specimen with less than 10 epithelial cells and more than 25 polymorphonuclear (PMN) cells per high power field to be optimal. Specimens with more than 10 epithelial cells are discarded, whereas those with few epithelial cells and few PMNs are processed (in particular if a history of neutropenia is provided), but specimen recollection is advised.

The use of "stat" sputum gram stains is very helpful for the detection of specific pathogens in patients with severe CAP. Empiric therapy may be altered based on gram stain morphology (eg, gram-positive cocci in clumps/clusters suggestive of $S$. aureus) and the local prevalence and resistance profiles of specific pathogens. Semiquantitative culture results are helpful in that most pathogens are present in at least $3+\left(>10\right.$ microorganisms per high-powered field) quantity. ${ }^{131}$

Sputum culture results must be interpreted with caution because many respiratory pathogens can colonize the upper and/or lower respiratory tracts. In addition, microorganisms that do not cause pulmonary disease, such as Candida species, coagulase-negative staphylococci, and enterococci, are commonly isolated in culture and should not be treated.

Respiratory culture yield is substantially higher in intubated versus unintubated patients. Endotracheal aspirates and bronchoscopic samples should be obtained as 
soon as possible following intubation. Interpretation may be improved with quantitative or semiquantitative cultures. ${ }^{132-134}$

Bronchoscopy should be pursued in patients with suspected pneumonia when specimens cannot be obtained or are nondiagnostic. Patients with immune compromise may require bronchoscopy for less common and more difficult to identify pathogens such as Mycobacterium tuberculosis, Pneumocystis jirovecii, or fungi. Bronchoscopy may also be used for the purpose of excluding other diagnoses such as malignancy, diffuse alveolar hemorrhage, or hypersensitivity pneumonitis.

Urinary antigen assays are available for S. pneumoniae and Legionella species. Advantages of urinary antigen testing in critically ill patients with severe CAP include the high sensitivity and specificity when compared with sputum gram stain and culture, rapid turn-around time, and positivity even after the initiation of antibiotics. ${ }^{135,136}$ The major disadvantage of urinary antigen testing is the lack of antibiotic susceptibility data compared with culture techniques. In addition, urinary antigen testing for Legionella is only able to detect serogroup 1; however this serogroup does account for approximately $80 \%$ of Legionella infections. ${ }^{137,138}$

Respiratory virus testing should be performed in all patients with severe CAP, especially during influenza season. Multiplex molecular techniques have become widely available, allowing for the simultaneous testing of multiple respiratory viruses with rapid turn-around times.

\section{SCORING SYSTEMS FOR SEVERITY ASSESSMENT, PROGNOSTIC SCORING, AND SITE OF CARE}

Indications for ICU admission vary among patients, clinicians, hospitals, and health care systems. ${ }^{27}$ For example, patient comorbidity burden, severity of disease, clinician comfort and experience, as well as the availability of intermediate care within an institution can all affect ICU admission rates for CAP.

Prompt recognition of patients with severe CAP is essential in optimizing outcomes. However, previous studies have shown that clinical judgment alone is not an accurate measure of pneumonia severity. As a result, numerous prognostic scoring systems have been developed to help stratify patients with CAP by severity and prognosis (mortality) as well as aid decisions on site of care (outpatient, ward, or ICU). The 2 best-studied prediction rules are the Pneumonia Severity Index (PSI) ${ }^{139}$ and the CURB-65. ${ }^{140}$

\section{Pneumonia Severity Index}

The PSI, derived in the United States by Fine and colleagues ${ }^{139}$ (Box 4), is a comprehensive score made up of demographic, physical, and laboratory findings. It stratifies patients into 5 classes according to mortality risk. Designed to identify low-risk patients who could be managed in an ambulatory setting, the PSI lacks the ability to discriminate among sicker patients. Class IV and V patients both warrant hospital admission, but the PSI is not helpful in further stratification by need for ICU admission. In addition, the PSI can easily underestimate severity of disease in young, previously healthy patients as a large number of points are allocated to age and comorbid disease burden. ${ }^{141}$

\section{CURB-65}

The CURB-65 (Box 5), developed by the British Thoracic Society, is somewhat simpler to calculate than the PSI, using only 5 pneumonia-specific criteria, each scoring one 


\begin{tabular}{|c|c|c|}
\hline Characteristic & & Points Assigned \\
\hline Demographic facto & & \\
\hline Age & & \\
\hline Men & & Age $(y)$ \\
\hline Women & & Age $(y)-10$ \\
\hline Nursing home resid & & +10 \\
\hline Coexisting illnesses & & \\
\hline Neoplastic diseas & & +30 \\
\hline Liver disease & & +20 \\
\hline Congestive heart & & +10 \\
\hline Cerebrovascular & & +10 \\
\hline Renal disease & & +10 \\
\hline Physical examinatio & & \\
\hline Altered mental st & & +20 \\
\hline Respiratory rate & & +20 \\
\hline Systolic blood pre & & +20 \\
\hline Temperature $<35$ & & +15 \\
\hline Pulse $\geq 125$ beats & & +10 \\
\hline Laboratory and rad & & \\
\hline Arterial $\mathrm{pH}<7.35$ & & +30 \\
\hline Blood urea nitros & & +20 \\
\hline $\mathrm{Na}<130 \mathrm{mmol} / \mathrm{L}$ & & +20 \\
\hline Glucose $\geq 250 \mathrm{mg}$ & & +10 \\
\hline Hematocrit $<30 \%$ & & +10 \\
\hline Partial pressure o & $\mathrm{Hg}^{c}$ & +10 \\
\hline Pleural effusion & & +10 \\
\hline Number of Points & Class & Mortality (\%) \\
\hline $0-50$ & I & 0.1 \\
\hline $51-70$ & II & 0.6 \\
\hline 71-90 & III & 0.9 \\
\hline $91-130$ & IV & 9.3 \\
\hline 131-395 & $\mathrm{V}$ & 27 \\
\hline
\end{tabular}

${ }^{a}$ Neoplastic disease defined as any cancer except basal or squamous cell cancer of the skin that was active at the time of presentation or diagnosed within 1 year of presentation. Liver disease defined as a clinical or histologic diagnosis of cirrhosis or another form of chronic liver disease, such as chronic active hepatitis. Congestive heart failure defined as systolic or diastolic ventricular dysfunction documented by history; physical examination; and chest radiograph, echocardiogram, multiple-gated acquisition scan, or left ventriculogram. Cerebrovascular disease defined as a clinical diagnosis of stroke or transient ischemic attack or stroke documented by magnetic resonance imaging or computed tomography. Renal disease defined as a history of chronic renal disease or abnormal blood urea nitrogen and creatinine concentrations.

${ }^{b}$ Altered mental status defined as disorientation with respect to person, place, or time that is not known to be chronic, stupor, or coma.

' In the Pneumonia Patient Outcomes Research Team cohort study, oxygen saturation less than $90 \%$ on pulse oximetry or intubation before admission was also considered abnormal.

point, including acute confusion, blood urea nitrogen level greater than $7 \mathrm{mmol} / \mathrm{L}$, respiratory rate greater than 30 breaths/min, systolic blood pressure less than $90 \mathrm{~mm} \mathrm{Hg}$ or diastolic blood pressure less than or equal to $60 \mathrm{~mm} \mathrm{Hg}$, and age more than 65 years. ${ }^{140}$ The CURB-65 appears to be more discriminatory compared with the PSI 


\begin{tabular}{ll}
\hline Box 5 & \\
CURB-65 & Points \\
\hline Clinical Factor & 1 \\
\hline Confusion & 1 \\
Blood urea nitrogen $>19 \mathrm{mg} / \mathrm{dL}$ & 1 \\
Respiratory rate $\geq 30$ breaths $/ \mathrm{min}$ & 1 \\
Systolic blood pressure $<90 \mathrm{~mm} \mathrm{Hg}$ & \\
or & \\
Diastolic blood pressure $\leq 60 \mathrm{~mm} \mathrm{Hg}$ & 1 \\
Age $\geq 65$ y & \\
Interpretation: 0-1, low risk, outpatient therapy mostly appropriate; 2, admit to hospital; 3 or \\
more, assess for care in ICU (especially if score 4-5).
\end{tabular}

among patients requiring hospital admission; with a score of greater than or equal to 3 denoting severe disease, which may warrant ICU admission. In contrast, the lack of comorbid disease burden in CURB-65 makes it easy to underestimate the mortality risk in elderly, frail patients who may decompensate significantly even with mild pneumonia. $^{142}$

\section{IDSAVATS Criteria}

Current IDSA/ATS guidelines propose their own set of criteria, suggesting that patients be admitted to the ICU if they have 1 major or 3 minor criteria (see Box 1). ${ }^{27}$ Major criteria include the need for mechanical ventilation or the presence of septic shock. Minor criteria include $\mathrm{PaO}_{2}: \mathrm{FiO}_{2}$ ratio less than 250, respiratory rate greater than 30 breaths/min, multilobar infiltrates, systolic blood pressure less than $90 \mathrm{~mm} \mathrm{Hg}$ despite aggressive fluid resuscitation, blood urea nitrogen level greater than $20 \mathrm{mg} / \mathrm{dL}$, leukopenia $\left(<4000\right.$ cells $\left./ \mathrm{mm}^{3}\right)$, thrombocytopenia $\left(<100,000\right.$ cells $\left./ \mathrm{mm}^{3}\right)$, and hypothermia $(<36 \mathrm{C})$. Numerous validation studies support the use of these criteria. ${ }^{143-146}$

\section{SMART-COP}

Other more recently derived prediction rules include SMART-COP (Box 6), a tool that aims to predict the need for intensive respiratory or vasopressor support (IRVS) in patients with CAP. ${ }^{147}$ This score was developed from a cohort of 862 patients with CAP, $10 \%$ of whom required IRVS. A maximum 11 points can be accrued based on the following criteria: systolic blood pressure less than $90 \mathrm{~mm} \mathrm{Hg}$, multilobar chest radiograph involvement, albumin less than $35 \mathrm{~g} / \mathrm{L}$, tachypnea, tachycardia greater than 125 beats/min, acute confusion, low oxygenation (based on age-adjusted $\mathrm{PaO}_{2}$, $\mathrm{SpO}_{2}$, and $\mathrm{PaO}_{2}: \mathrm{FiO}_{2}$ ratios), and $\mathrm{pH}$ less than 7.35. The authors defined severe CAP as a score of greater than or equal to 5 , and $92 \%$ of patients who received IRVS scored greater than equal to 3 . A recent meta-analysis demonstrated similar sensitivity and specificity of IDSA/ATS criteria and SMART-COP, both of which outperformed PSI and CURB-65. Further validation, however, is required.

\section{Predisposition, Insult, Response, and Organ Dysfunction}

Predisposition, insult, response, and organ dysfunction (PIRO) was recently developed to predict 28-day mortality specifically among severe CAP patients requiring admission to the ICU (Box 7). ${ }^{148}$ With a maximum score of 8 , variables including comorbidity (COPD, immune compromise), age greater than 70 years, multilobar disease, shock, severe hypoxemia, acute renal failure, bacteremia, and ARDS each 


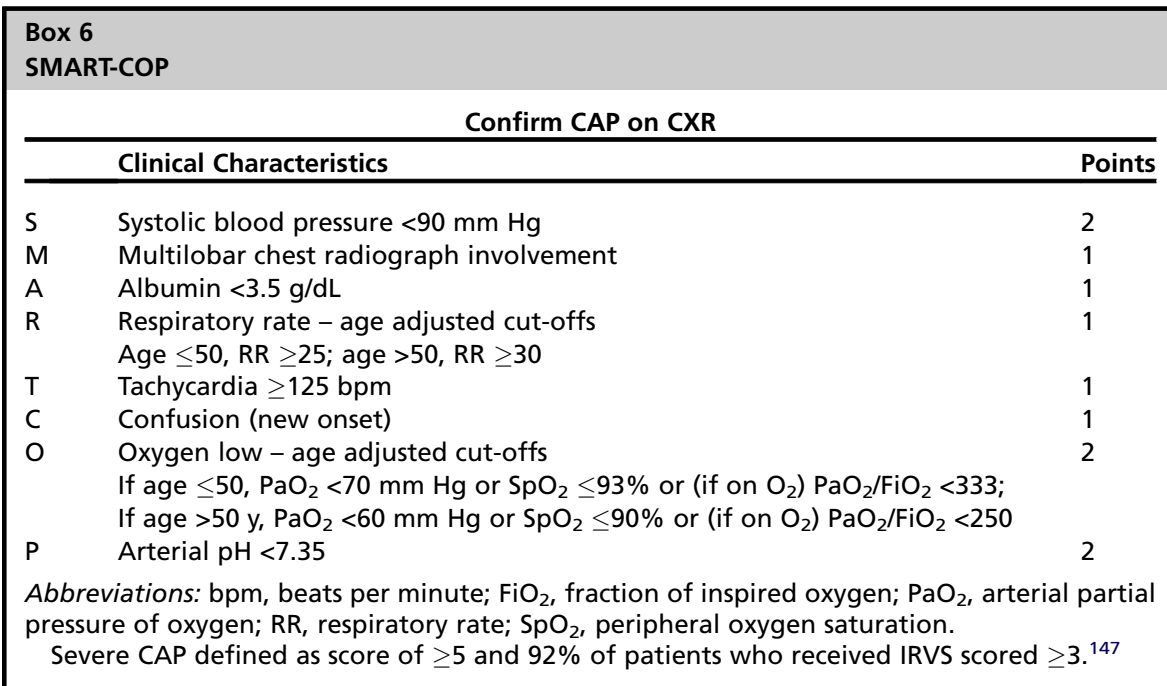

score one point. The PIRO score performed well as a 28-day mortality prediction tool in CAP patients requiring ICU admission and outperformed both APACHE II and ATS/ IDSA criteria ${ }^{148}$; however, validation studies are required.

\section{Additional Severity Indicators}

Additional criteria that suggest severe disease and potential need for ICU admission include hypoglycemia (in the nondiabetic patient), lactate greater than $4 \mathrm{mmol} / \mathrm{L}$, $\mathrm{Na}$ less than $130 \mathrm{mEq} / \mathrm{L}$, arterial $\mathrm{pH}$ less than 7.3, cirrhosis, and asplenia. In addition, severe hypoxia or the need for high-flow oxygen should be considered when deciding on site of care. The need for frequent and invasive clinical and/or laboratory monitoring in patients at high risk of decompensation may also warrant ICU admission.

\begin{tabular}{|c|c|c|c|}
\hline \multicolumn{4}{|l|}{$\begin{array}{l}\text { Box } 7 \\
\text { PIRO }\end{array}$} \\
\hline \multicolumn{2}{|c|}{ Variables } & & Points \\
\hline \multicolumn{2}{|c|}{ Comorbidities (COPD, immunocompromise) } & & 1 \\
\hline \multicolumn{2}{|c|}{ Age $>70$ y } & & 1 \\
\hline \multicolumn{2}{|c|}{ Multilobar opacities on chest radiograph } & & 1 \\
\hline \multicolumn{2}{|c|}{ Shock } & & 1 \\
\hline \multicolumn{2}{|c|}{ Severe hypoxemia } & & 1 \\
\hline \multicolumn{2}{|c|}{ Acute renal failure } & & 1 \\
\hline \multicolumn{2}{|c|}{ Bacteremia } & & 1 \\
\hline \multicolumn{2}{|c|}{ Acute respiratory distress syndrome } & & 1 \\
\hline Score & Risk & & lity (\%) \\
\hline $0-2$ & Low & 3.6 & \\
\hline 3 & Moderate & 13 & \\
\hline 4 & High & 43 & \\
\hline $5-8$ & Very high & 76 & \\
\hline
\end{tabular}


In addition to the pneumonia prediction rules discussed, numerous severity scores are available specifically for the assessment of critically ill patients, the most popular

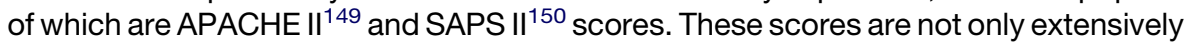
used but also well validated and may be used to predict mortality in critically ill patients with CAP. These scores also serve to compare critically patients across units or regions.

Although objective scores are very helpful in assessing severity and deciding on site of care, they should always be used in combination with physician assessment.

\section{ANTIMICROBIAL MANAGEMENT Empiric Therapy}

Empiric antimicrobial therapy should be initiated as quickly as possible in patients with severe CAP. Guidelines for the management of CAP have been published by various organizations, most notably by the IDSA/ATS ${ }^{27}$ and the British Thoracic Society. ${ }^{151}$ Locally adapted guidelines, incorporating local epidemiology should be implemented whenever possible.

For the empiric therapy of severe CAP, IDSA/ATS guidelines suggest an intravenous beta-lactam (cefotaxime, ceftriaxone, ampicillin/sulbactam) plus either a macrolide (azithromycin) or a respiratory fluoroquinolone (Box 8). ${ }^{27}$ In patients with significant penicillin allergies, a respiratory fluoroquinolone and aztreonam are recommended.

Although $5 \%$ to $10 \%$ of patients report penicillin allergy, studies show $85 \%$ to $90 \%$ of these individuals are in fact able to tolerate penicillins. ${ }^{152,153}$ In addition, the prevalence of immediate immunoglobulin E-mediated penicillin allergy (characterized by pruritus, flushing, urticaria, angioedema, laryngeal edema, and/or hypotension) appears to be declining. ${ }^{154,155}$ Cross-reactivity with other beta-lactams, when used in penicillin-allergic patients, has been historically overestimated; more recent studies suggest third-generation cephalosporins and carbapenems have low rates of cross-reactivity $(\leq 1 \%) .{ }^{156-158}$ Nonetheless, a graded challenge may be appropriate in patients deemed to be high risk.

In patients at risk for $P$. aeruginosa treatment should include an antipseudomonal beta-lactam (cefepime, imipenem, meropenem, piperacillin/tazobactam) plus an anti-pseudomonal fluoroquinolone or aminoglycoside. Either a macrolide (azithromycin) or a respiratory fluoroquinolone should be added in patients treated with

BoX 8

IDSA/ATS recommended empiric therapy for severe pneumonia (ICU patients)

Beta-lactam (cefotaxime, ceftriaxone, or ampicillin/sulbactam) plus azithromycin or a respiratory fluoroquinolone

For penicillin-allergic patients, a respiratory fluoroquinolone and aztreonam

If Pseudomonas is a consideration

An antipneumococcal, antipseudomonal beta-lactam (piperacillin/tazobactam, cefepime, imipenem, or meropenem) plus either ciprofloxacin or levofloxacin (750 mg)

OR

Above beta-lactam plus an aminoglycoside and azithromycin

OR

Above beta-lactam plus an aminoglycoside and an antipneumococcal fluoroquinolone (for penicillin-allergic patients, substitute aztreonam for above beta-lactam)

If CA-MRSA considered, add vancomycin or linezolid 
beta-lactam/aminoglycoside combinations to ensure adequate empiric atypical coverage. Aztreonam can be substituted for the above beta-lactams in patients with serious penicillin allergy.

In those at risk for CA-MRSA, treatment with either linezolid or vancomycin should be initiated. Historically, vancomycin has been the drug of choice in patients with MRSA CAP given substantial clinical experience. However, a recent randomized clinical trial demonstrated improved cure rates and less nephrotoxicity, but no difference in mortality, with the use of linezolid compared with vancomycin in MRSA nosocomial pneumonia. ${ }^{159}$ Generalization of these results to patients with CAP, however, must be done with caution.

An additional theoretical benefit of linezolid in the treatment of CA-MRSA pneumonia is its ability to decrease toxin production ${ }^{160-162}$, which would be particularly desirable in infections due to PVL-positive CA-MRSA strains. Linezolid is also preferred for strains with higher vancomycin MICs (termed "MIC creep"), because clinical failures have been reported with MICs greater than or equal to $1.5 \mathrm{mcg} / \mathrm{mL}$. ${ }^{163-165}$ When vancomycin is used, target trough levels should be optimized with a goal of 15 to $20 \mathrm{mcg} / \mathrm{mL}$.

Alternate agents for the treatment of CA-MRSA infection include telavancin and ceftaroline. Clindamycin and trimethoprim/sulfamethoxazole may also be used in patients with mild disease and susceptible isolates. Daptomycin is not effective for the treatment of pneumonia because it is inactivated by pulmonary surfactant.

Tigecycline should be used with extreme caution given the recent warning issued by the US Food and Drug Administration regarding increased mortality associated with its use for a variety of serious infections. ${ }^{166}$ This announcement was based on a pooled analysis of 13 clinical trials, in which tigecycline was given for both approved and unapproved indications. Overall risk of death was higher in patients receiving tigecycline versus comparator antibiotics (4.0\% vs 3.0\%; RD 0.6; $95 \%$ confidence interval [Cl] $0.1,1.2)$. Although there was no difference in mortality among patients with CAP $(2.8 \%$ vs $2.6 \%$; RD $0.2 ; 95 \% \mathrm{Cl} 2.0,2.4)$, the use of tigecycline in the treatment of CAP is discouraged. ${ }^{167}$

Empiric therapy for influenza should be initiated with a neuraminidase inhibitor in patients with compatible clinical syndromes during influenza season. In critically ill patients who require invasive mechanical ventilation, oseltamivir is preferred because zanamivir inhalation powder can clog ventilator tubing and has been associated with adverse events. ${ }^{168,169}$

Early initiation of antiviral therapy (within 48 hours of symptom onset) is most efficacious $^{170-174}$; however, all critically ill patients with suspected influenza should be treated empirically regardless of timing from symptom onset. Delayed antiviral therapy, although not as beneficial as early therapy, still appears to improve survival in critically ill patients. ${ }^{175}$ Antiviral therapy has also been shown to decrease the duration of viral shedding. ${ }^{176,177}$ Treatment should be discontinued if nucleic acid amplification testing is negative or continued for a total of 5 to 10 days in confirmed cases. Although guidelines ${ }^{178}$ recommended high-dose oseltamivir in critically ill patients during the H1N1/09 pandemic, more recent studies have demonstrated adequate serum levels with standard doses. ${ }^{179,180}$ Droplet and contact isolation should be used to prevent nosocomial transmission. Additional airborne precautions are recommended during aerosolgenerating procedures, ${ }^{181}$ despite a lack of data to support this approach.

\section{Combination Therapy}

Combination therapy in severe CAP has been associated with improved outcomes in patients with bacteremic pneumococcal pneumonia, predominantly with 
macrolide-containing combination regimens. Despite increasing macrolide resistance, treatment efficacy in patients with pneumococcal CAP continues to be demonstrated. ${ }^{182}$ This benefit is thought to be due to immunomodulation as macrolides have been shown to downregulate leukocyte adhesion and inhibit inflammatory cytokine production, thereby decreasing inflammatory responses. ${ }^{182,183}$

Indeed, macrolides have been shown to improve outcomes in chronic pulmonary inflammatory conditions such as asthma, ${ }^{184}$ COPD, ${ }^{185}$ diffuse panbronchiolitis, and bronchiectasis. ${ }^{186}$ More recent studies have demonstrated a mortality benefit with macrolide-based treatment acutely, specifically in the treatment of severe pneumonia, compared with nonmacrolide-based therapies. ${ }^{66,67,187,188}$ Furthermore, it appears that the most impressive effect exists in patients with severe disease or shock, those with a presumably more robust systemic inflammatory response. However, many of these studies are observational and therefore prone to confounding.

In addition, the greater potential for antimicrobial toxicity needs to be considered when prescribing combination therapies in the absence of high-level evidence. For example, macrolides have long been associated with QTC interval prolongation. A recent study ${ }^{189}$ demonstrated an increase in risk of cardiovascular death in patients with upper respiratory infection who received azithromycin. Those with baseline cardiovascular risk factors were at highest risk. Whether critically ill patients might also be at higher risk, in particular given the concomitant use of other QTc prolonging medications in the ICU, is not known.

Other studies suggest that guideline concordance or any combination therapy (targeting both typical and atypical CAP pathogens), irrespective of specific treatment regimen, is most closely associated with improved outcomes. ${ }^{187,190-195}$

\section{Pathogen-Directed Therapy}

Pathogen-directed therapy should be prescribed if etiologic information becomes available. The narrowest spectrum agent should be used to prevent the development of antimicrobial resistance.

\section{Timing}

Effective antimicrobial therapy should be administered as quickly as possible in patients with severe CAP. Various studies have demonstrated increased mortality in critically ill patients who receive delayed antimicrobial therapy. ${ }^{196-199}$ Specifically, in critically ill patients with CAP, the administration of effective antibiotics within 4 hours of admission, compared with delayed therapy, was associated with decreased mortality. ${ }^{198}$ IDSA/ATS guidelines suggest that, for patients admitted through the Emergency Department (ED), the first dose of antibiotic should ideally be administered while still in the ED. ${ }^{27}$ A specific time threshold was specifically avoided but studies suggest less than 4 hours may be a reasonable goal. ${ }^{199}$

\section{Step Down to Enteral Therapy}

Switch to enteral antimicrobial therapy should be considered in all patients once hemodynamically stable and clinically improving (ie, absence of fever for 72 hours and reduction in respiratory symptoms). Numerous studies in CAP have demonstrated safety with this approach, ${ }^{200-202}$ including in patients with severe (PSI class V) disease. 202

Access to and function of the gastrointestinal tract are necessary (patients who remain intubated require naso-gastric or oro-gastric tube placement). Specific antimicrobial bioavailability properties need to be carefully considered when choosing optimal regimens. Antimicrobials with excellent bioavailability include the 
fluoroquinolones, clindamycin, metronidazole, linezolid, and trimethoprim/sulfamethoxazole. Generally, beta-lactams have poor bioavailability. Other antimicrobials are only available in intravenous formulation for the treatment of systemic infections (such as aminoglycosides or vancomycin).

\section{NonResponse}

Nonresponse is common in patients with CAP, occurring in 6\% to $15 \%$ of hospitalized patients ${ }^{203,204}$ and approximately $40 \%$ of ICU patients, ${ }^{205}$ and mortality rates are higher in nonresponders compared with responders. ${ }^{203}$ The lack of a clear definition of nonresponse makes it difficult, however, to compare populations and fully understand the epidemiology of nonresponse.

IDSA/ATS guidelines ${ }^{27}$ propose 2 main patterns of nonresponse based on several studies. ${ }^{203-205}$ First is progressive pneumonia or clinical deterioration, with acute respiratory failure requiring ventilatory support and/or concomitant septic shock, usually within 72 hours of hospital admission. ${ }^{27}$ These are the patients who are initially admitted to hospital wards but who eventually require ICU admission because of deterioration. Clinical worsening after 72 hours is more likely related to complications (such as parapneumonic effusion or empyema), decompensation of underlying comorbid disease, or secondary nosocomial infection.

Second, patients may clinically deteriorate due to persistent or nonresponding pneumonia, defined as an absence of or delay in achieving clinical stability. ${ }^{27}$ Risk factors for nonresponse include older age (>65 years), multilobar pneumonia, greater disease severity, liver disease, cavitary disease, parapneumonic effusion or empyema, leukopenia, gram-negative infection (in particular resistant microorganisms), Legionella pneumonia, and guideline discordant antimicrobial therapy. ${ }^{203-205}$ In addition, the possibility of inaccurate diagnosis needs to be considered in these patients.

The management of the nonresponding patient includes further diagnostic testing to identify the cause of pneumonia (if not determined on initial presentation), rule out the development of resistance on therapy, and to exclude complications such as empyema or nosocomial superinfection. CT scanning of the chest, thoracentesis, and bronchoscopy may be helpful. An inadequate host response, however, is the most common cause of nonresponse in patients treated with guideline concordant therapies. Empiric antimicrobial therapy escalation may be appropriate while diagnostic test results are pending.

\section{Duration}

Most patients with CAP receive 7 to 10 days of antimicrobial therapy, but little data or guidelines are available for critically ill patients who have traditionally received longer courses of therapy. Duration of therapy should depend on disease severity, antimicrobial properties (half-life, bacteriostatic vs bactericidal action), patient immune adequacy, and clinical response.

Clinical response should be observed within the first 2 to 3 days. A large metaanalysis of 15 randomized trials in patients with CAP found no difference in outcome between less than or more than 7 days of therapy; however, only two trials included hospitalized patients, neither of which included ICU patients. ${ }^{206}$

A subsequent Cochrane review, examining short-course (7-8 days) versus prolonged-course (10-15 days) therapy for hospital-acquired pneumonia in more than 1700 critically ill patients, demonstrated reduced ventilator-associated pneumonia (VAP) recurrence due to multiresistant organisms, increased 28-day antibiotic-free days, and no difference in mortality with short-course therapy. However, 
recurrence of VAP due to glucose nonfermenting gram-negative bacilli was greater after short-course therapy. ${ }^{128}$ Based on these data we would suggest a similar approach in patients with CAP. Therefore, longer courses of therapy should be considered in CAP due to glucose nonfermenters ( $P$. aeruginosa, Acinetobacter baumannii, Burkholderia), $S$. aureus, ${ }^{207}$ Legionella, and fungi. In addition, patients with necrotizing pneumonia, empyema, lung abscess, ${ }^{208}$ or extrapulmonary infection (bacteremia, meningitis, endocarditis) require longer courses.

In summary, treatment duration should be individualized based on patient characteristics, microbial cause, and clinical response. Antimicrobial stewardship programs can help decrease duration and narrow spectrum of antimicrobial therapy. ${ }^{209}$

\section{ADDITIONAL THERAPIES \\ Acute Respiratory Distress Syndrome}

Pneumonia is the most common cause of ARDS. ${ }^{210-212}$ Patients who develop ARDS should be treated with low-volume, open-lung ventilation strategies. ${ }^{212}$ In patients who do not respond to conventional ventilation, salvage techniques including airway-pressure release ventilation, high-frequency oscillatory ventilation, prone positioning, or inhaled nitric oxide may be used; however none of these strategies have been shown to improve survival.

\section{Severe Sepsis and Septic Shock}

In patients with severe sepsis or septic shock, early goal-directed therapy, a resuscitation strategy involving goal-oriented manipulation of cardiac preload, afterload, and contractility to achieve a balance between systemic oxygen delivery and oxygen demand, has been shown to significantly improve outcomes. ${ }^{213}$ In addition, corticosteroid supplementation should be administered in patients with vasopressor-dependent shock as studies have demonstrated decreased time to shock reversal without an increase in adverse events. ${ }^{214-217}$

\section{Steroids}

The role of glucocorticoids as adjunctive therapy in severe CAP in the absence of septic shock has not been well defined. Previous studies have suggested a modest mortality benefit in severe CAP ${ }^{218,219}$ while others were unable to reproduce this, ${ }^{220-222}$ and in fact demonstrated higher rates of late failure. ${ }^{220}$ Given the paucity of data, there is no convincing evidence to suggest the use of adjunctive glucocorticoids specifically for severe CAP in the absence of septic shock at this time.

\section{Extracorporeal Membrane Oxygenation}

Extracorporeal membrane oxygenation (ECMO) has been evaluated as a treatment of severe respiratory failure and ARDS. The recently published Conventional ventilatory support versus Extracorporeal membrane oxygenation for Severe Acute Respiratory failure $^{223}$ (CESAR) trial randomized 180 patients with severe respiratory failure $(60 \%$ of whom had pneumonia) to ECMO versus conventional management.

Severe acute respiratory failure was defined as hypercapnic respiratory acidosis with an arterial $\mathrm{pH}$ less than 7.2 or severe hypoxia as measured by a Murray score greater than 3 (points allotted based on $\mathrm{PaO}_{2} / \mathrm{FiO}_{2}$ ratio, level of positive endexpiratory pressure, lung compliance, and chest radiography). Patients who were elderly (>65 years), intubated longer than 7 days, or had contraindications to anticoagulation were excluded. Those who received ECMO had a significantly lower mortality compared with controls (47 vs $63 \% ; P=.03$ ). 
A subsequent cohort study of 75 matched pairs with H1N1/09 ARDS similarly demonstrated a lower mortality rate (23.7 vs $52.5 \% ; P=.006)$ in patients who received ECMO. ${ }^{224}$

Whether or not ECMO will become more available for patients with severe, potentially reversible, acute respiratory failure, including CAP, that is unresponsive to conventional management remains to be answered. For patients in medical centers with ECMO availability the authors advocate this therapy in select patients. For those who require transfer to an ECMO center, the additional risks of patient transfer need to be carefully considered.

\section{Supportive Care}

Thromboembolism prophylaxis, stress ulcer prophylaxis, and early enteral feeding should be used in all critically ill patients unless contraindicated. Assisted organ support should be provided via mechanical ventilation, renal replacement therapy, and vasoactive medications. A summarized, comprehensive approach to the treatment of patients with severe CAP is suggested in Box 9.

\section{PREVENTION}

\section{Smoking Cessation}

Cigarette smoking is the leading cause of preventable mortality, resulting in more than 400,000 deaths per year in the United States. ${ }^{225}$ Physicians should address smoking status and counsel patients regarding cessation while in hospital. Combined behavioral support and pharmacologic therapy has been shown to increase success rates. $^{226}$

\section{Vaccination}

Vaccinations should be provided to patients admitted with CAP, preferably before hospital discharge, if such immunizations are not up to date.

Two types of pneumococcal vaccine are available: polysaccharide and conjugate preparations. Vaccination with pneumococcal polysaccharide vaccine in adults has been shown to induce elevated and persistent functional antibody responses ${ }^{227,228}$

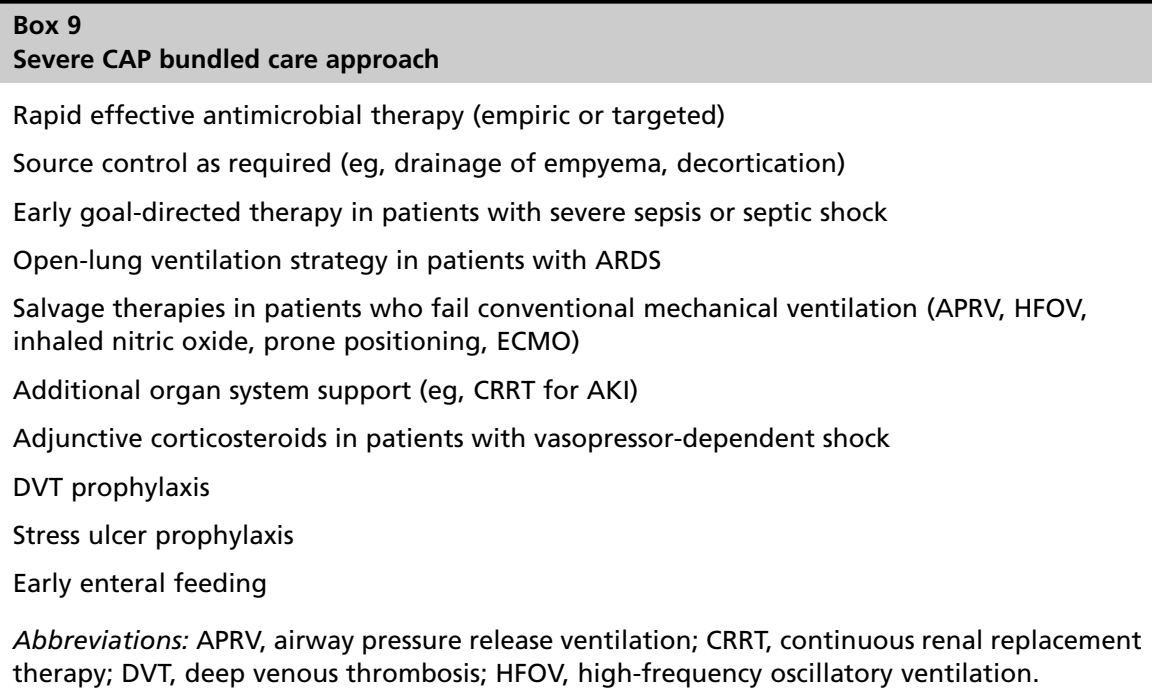


and protect against invasive pneumococcal disease. ${ }^{229,230}$ Conjugate vaccines were developed specifically for improved immunogenicity in children.

The 23-valent polysaccharide vaccine (PPSV23) is recommended for all adults 65 years of age and older and for adults less than 65 years of age in long-term care facilities or at high risk of invasive pneumococcal disease. High-risk conditions include chronic alcoholism, cigarette smoking, homelessness, asthma, injection drug use, chronic cerebrospinal fluid leak, chronic neurologic conditions, the presence of cochlear implants, chronic cardiac or pulmonary disease, diabetes, asplenia, sickle cell disease or other hemoglobinopathy, congenital or acquired immunodeficiency (including transplant patients, those with HIV, or those receiving immunosuppressive therapies), chronic kidney or liver disease, or malignant neoplasm. ${ }^{231}$ A single revaccination with PPSV23 is recommended 5 years after the first dose for persons aged 19 to 64 years with functional or anatomic asplenia and for persons with immunocompromising conditions. ${ }^{231}$

In addition, the United States Advisory Committee on Immunization Practices recommends dual vaccination with PPSV23 and 13-valent conjugate vaccine (PCV13) in adults with immunocompromising conditions (eg, HIV infection, cancer, functional or anatomic asplenia, solid organ transplantation), cerebrospinal fluid leaks, cochlear implants, chronic renal insufficiency, or nephrotic syndrome ${ }^{232}$ because these patients may not have an adequate response to polysaccharide vaccine.

Illness due to CAP, either isolated or recurrent, is not considered an indication for pneumococcal vaccination; however given little downside, the authors suggest routine vaccination of all patients following CAP, preferably at the time of hospital discharge.

Influenza vaccine should be administered yearly to all individuals 6 months of age and older although high-risk individuals, their close contacts, and health care workers should be prioritized. ${ }^{233}$

\section{Infection Control}

Infection control measures including effective hand and respiratory hygiene as well as appropriate isolation (droplet, contract, or airborne, depending on the microorganism) help to prevent the spread of infection in hospital. In addition, nosocomial infection prevention strategies for hospital-associated and ventilator-associated pneumonia, central line-associated bloodstream infections, and catheter-related urinary tract infections should be practiced.

\section{SURGICAL INDICATIONS AND THERAPY}

Surgical intervention is rarely required in the treatment of severe CAP. The main indication for surgical intervention is to achieve source control in the setting of empyema or lung abscess/necrosis. Empyema drainage can be achieved via tube thoracostomy (large bore chest tubes are required due to high viscosity) with or without intrapleural tissue plasminogen activator administration. Decortication may be required if tube thoracostomy is not successful. For lung abscess or necrotizing pneumonia, thoracotomy and wedge resection is occasionally required. Lastly, for cases of suspected pneumonia in which patients are unresponsive to empiric therapy and bronchoscopic investigations are nondiagnostic, video-assisted thoracic surgery or open lung biopsy may be required for diagnostic purposes.

\section{OUTCOMES}

Clinical outcomes in patients with severe CAP include mortality (hospital, ICU, 30-day, and long-term eg, 1 year, 5 years), rates of hospital and ICU admission, delayed 
transfers to ICU, treatment failure, drug toxicities and adverse effects of therapy, antibiotic resistance, hospital and ICU lengths of stay, 30-day readmission rates, unscheduled returns to ED or primary physician office, time to return to normal daily activities, patient satisfaction, and costs of care. ${ }^{27}$ Although all are important, mortality is the most commonly studied outcome and undeniably the hardest endpoint.

Mortality in ICU patients with CAP is higher compared with patients admitted to hospital wards ${ }^{21,64,234}$ and ranges from $11 \%$ to $56 \% .^{11,21-26}$ Various predictors of mortality in patients with severe CAP include advanced age, ${ }^{16,20,24}$ poor functional status, ${ }^{25,235-238}$ disease severity, ${ }^{20,239}$ multilobar or bilateral consolidation on chest radiograph, ${ }^{24,240}$ immune compromise, ${ }^{20}$ presence of renal failure, ${ }^{240}$ need for mechanical ventilation, ${ }^{239}$ hypotension/shock, ${ }^{239,240}$ and nonadherence to guidelines. $^{20,191,241}$

Multiple organ dysfunction syndrome (MODS) is common in patients with severe sepsis and septic shock and was demonstrated in $17 \%$ of patients admitted with severe CAP in one study. ${ }^{19}$ Organ-specific criteria for the diagnosis of MODS include measures of $\mathrm{PaO}_{2} / \mathrm{FiO}_{2}$ ratio, serum creatinine, platelet count, Glasgow coma score, serum bilirubin, and heart rate. ${ }^{242}$ The Sequential Organ Failure Assessment Score is commonly used to assess the incidence and severity of organ dysfunction in critically ill patients. ${ }^{243}$ The development of MODS has been correlated both with ICU and hospital mortality. 242

Common pulmonary complications of severe CAP include empyema, lung abscess, pneumothorax, ARDS, and chronic respiratory failure requiring tracheostomy and prolonged mechanical ventilation. ${ }^{244}$ Patients who require prolonged mechanical ventilation may require specialty pulmonary wards for prolonged weaning and, not surprisingly, have high mortality rates. ${ }^{245,246}$

In addition, major cardiac complications, such as acute coronary syndromes, congestive heart failure and, cardiac arrhythmias, occur in a considerable number of patients with CAP, 65,247-249 likely the result of cardiac stress, cellular hypoxia, and inflammation. Critically ill CAP patients with cardiac complications are at particularly high risk and suffer worse outcomes when compared with non-ICU CAP cohorts. ${ }^{65,247,248}$ Recognition of this association may improve timely recognition and treatment of events, as well as prevention in high-risk populations.

Patients with delayed ICU admission (ie, those who are not directly admitted to the ICU, but transferred after 24-48 hours of hospitalization) seem to have higher morbidity and mortality. ${ }^{250,251}$ Up to $45 \%$ of patients with CAP requiring ICU are initially admitted to medical wards. ${ }^{252}$ Improving our ability to identify these patients at the time of hospital admission should be a priority.

Lastly, prognosis has also been shown to correlate with microbial cause (highest mortality with gram-negative infections), ${ }^{234}$ nonresponse to therapy at 72 hours (worse outcomes), ${ }^{203}$ and vaccination status. In a large population-based cohort study, individuals who had previously received pneumococcal vaccine had a $40 \%$ lower rate of mortality or ICU admission compared with those who had not been vaccinated. ${ }^{253}$

\section{SUMMARY}

Up to $22 \%$ of patients with CAP require ICU admission, with $44 \%$ to $83 \%$ requiring mechanical ventilation and up to $50 \%$ presenting with concomitant septic shock. Typical and atypical causative microorganisms responsible for CAP are predictable based on patient risk factors. Various scoring systems (such as the PSI, CURB-65, IDSA/ATS criteria) are available to help define CAP severity, prognosis, and site of care. 
Diagnosis of CAP in critically ill patients should be comprehensive and include clinical features plus radiographic, laboratory, and microbiologic testing. Empiric antimicrobial therapy should be initiated as quickly as possible, with adherence to IDSA ATS guidelines wherever possible. Targeted antimicrobial therapy should be prescribed once a microbial cause is identified. Source control, adjunctive therapies, and assisted organ support should be included in the care of the critically ill CAP patient.

Common complications suffered by patients with severe CAP include empyema, lung abscess, pneumothorax, ARDS, chronic respiratory failure requiring tracheostomy, cardiac complications (such as acute coronary syndromes, congestive heart failure, and arrhythmias), and multisystem organ failure. Prevention strategies need to be emphasized.

\section{REFERENCES}

1. File TM Jr, Marrie TJ. Burden of community-acquired pneumonia in North American adults. Postgrad Med 2010;122:130-41.

2. Heron M, Hoyert DL, Murphy SL, et al. Deaths: final data for 2006. Natl Vital Stat Rep 2009;57:1-134.

3. Minino AM, Murphy SL, Xu J, et al. Deaths: final data for 2008. Natl Vital Stat Rep 2011;59:1-126.

4. Average length of stay and days of care - Number and rate of discharges by first-listed diagnostic categories. Centers for Disease Control and Prevention, 2009. Available at: http://www.cdc.gov/nchs/fastats/pneumonia.htm. Accessed October 20, 2012.

5. Grossman RF, Rotschafer JC, Tan JS. Antimicrobial treatment of lower respiratory tract infections in the hospital setting. Am J Med 2005;118(Suppl 7A):29S-38S.

6. Ewig S, Woodhead M, Torres A. Towards a sensible comprehension of severe community-acquired pneumonia. Intensive Care Med 2011;37:214-23.

7. Aronsky D, Dean NC. How should we make the admission decision in community-acquired pneumonia? Med Clin North Am 2001;85:1397-411.

8. Niederman MS, McCombs JS, Unger AN, et al. The cost of treating communityacquired pneumonia. Clin Ther 1998;20:820-37.

9. Marston BJ, Plouffe JF, File TM Jr, et al. Incidence of community-acquired pneumonia requiring hospitalization. Results of a population-based active surveillance Study in Ohio. The Community-Based Pneumonia Incidence Study Group. Arch Intern Med 1997;157:1709-18.

10. Almirall J, Bolibar I, Vidal J, et al. Epidemiology of community-acquired pneumonia in adults: a population-based study. Eur Respir J 2000;15:757-63.

11. Ioachimescu OC, loachimescu AG, Iannini PB. Severity scoring in communityacquired pneumonia caused by Streptococcus pneumoniae: a 5-year experience. Int J Antimicrob Agents 2004;24:485-90.

12. Lamy O, Van Melle G, Cornuz J, et al. Clinical management of immunocompetent hospitalized patients with community-acquired pneumonia. Eur J Intern Med 2004;15:28-34.

13. Bratzler DW, Ma A, Nsa W. Initial antibiotic selection and patient outcomes: observations from the National Pneumonia Project. Clin Infect Dis 2008; 47(Suppl 3):S193-201.

14. Capelastegui A, Espana PP, Quintana JM, et al. Evaluation of clinical practice in patients admitted with community-acquired pneumonia over a 4-year period. Arch Bronconeumol 2006;42:283-9 [in Spanish]. 
15. Cilloniz C, Ewig S, Ferrer M, et al. Community-acquired polymicrobial pneumonia in the intensive care unit: aetiology and prognosis. Crit Care 2011;15:R209.

16. SligI WI, Eurich DT, Marrie TJ, et al. Age still matters: prognosticating short- and long-term mortality for critically ill patients with pneumonia. Crit Care Med 2010; 38:2126-32.

17. Woodhead M, Welch CA, Harrison DA, et al. Community-acquired pneumonia on the intensive care unit: secondary analysis of 17,869 cases in the ICNARC Case Mix Programme Database. Crit Care 2006;10(Suppl 2):S1.

18. Diaz A, Barria P, Niederman M, et al. Etiology of community-acquired pneumonia in hospitalized patients in chile: the increasing prevalence of respiratory viruses among classic pathogens. Chest 2007;131:779-87.

19. Rello J, Catalan M, Diaz E, et al. Associations between empirical antimicrobial therapy at the hospital and mortality in patients with severe communityacquired pneumonia. Intensive Care Med 2002;28:1030-5.

20. Bodi M, Rodriguez A, Sole-Violan J, et al. Antibiotic prescription for communityacquired pneumonia in the intensive care unit: impact of adherence to Infectious Diseases Society of America guidelines on survival. Clin Infect Dis 2005;41: 1709-16.

21. Angus DC, Marrie TJ, Obrosky DS, et al. Severe community-acquired pneumonia: use of intensive care services and evaluation of American and British Thoracic Society Diagnostic criteria. Am J Respir Crit Care Med 2002;166: 717-23.

22. Lee JH, Ryu YJ, Chun EM, et al. Outcomes and prognostic factors for severe community-acquired pneumonia that requires mechanical ventilation. Korean J Intern Med 2007;22:157-63.

23. Valencia M, Badia JR, Cavalcanti M, et al. Pneumonia severity index class v patients with community-acquired pneumonia: characteristics, outcomes, and value of severity scores. Chest 2007;132:515-22.

24. Wilson PA, Ferguson J. Severe community-acquired pneumonia: an Australian perspective. Intern Med J 2005;35:699-705.

25. Sligl WI, Eurich DT, Marrie TJ, et al. Only severely limited, premorbid functional status is associated with short- and long-term mortality in patients with pneumonia who are critically ill: a prospective observational study. Chest 2011;139: 88-94.

26. Pascual FE, Matthay MA, Bacchetti $P$, et al. Assessment of prognosis in patients with community-acquired pneumonia who require mechanical ventilation. Chest 2000;117:503-12.

27. Mandell LA, Wunderink RG, Anzueto A, et al. Infectious Diseases Society of America/American Thoracic Society consensus guidelines on the management of community-acquired pneumonia in adults. Clin Infect Dis 2007;44(Suppl 2): S27-72.

28. Respiratory Disease in Canada: Canadian Institute for Health Information. Available at: https://secure.cihi.ca/estore/productSeries.htm?pc=PCC33. Accessed October 30, 2012.

29. Dodek PM, Norena M, Keenan SP, et al. Intensive care unit admissions for community-acquired pneumonia are seasonal but are not associated with weather or reports of influenza-like illness in the community. J Crit Care 2011; 26:228-33.

30. Marrie TJ, Huang JQ. Epidemiology of community-acquired pneumonia in Edmonton, Alberta: an emergency department-based study. Can Respir J 2005;12:139-42. 
31. Marrie TJ, Durant H, Williams JC, et al. Exposure to parturient cats: a risk factor for acquisition of $Q$ fever in Maritime Canada. J Infect Dis 1988;158:101-8.

32. Albrich WC, Madhi SA, Adrian PV, et al. Use of a rapid test of pneumococcal colonization density to diagnose pneumococcal pneumonia. Clin Infect Dis 2012;54:601-9.

33. Werno AM, Anderson TP, Murdoch DR. Association between pneumococcal load and disease severity in adults with pneumonia. J Med Microbiol 2012;61:1129-35.

34. Waterer G, Rello J. Why should we measure bacterial load when treating community-acquired pneumonia? Curr Opin Infect Dis 2012;24:137-41.

35. Nimmo GR. USA300 abroad: global spread of a virulent strain of communityassociated methicillin-resistant Staphylococcus aureus. Clin Microbiol Infect 2012;18:725-34.

36. Kreienbuehl L, Charbonney E, Eggimann P. Community-acquired necrotizing pneumonia due to methicillin-sensitive Staphylococcus aureus secreting Panton-Valentine leukocidin: a review of case reports. Ann Intensive Care 2011;1:52.

37. Hatchette TF, Gupta R, Marrie TJ. Pseudomonas aeruginosa communityacquired pneumonia in previously healthy adults: case report and review of the literature. Clin Infect Dis 2000;31:1349-56.

38. Kunimasa K, Yoshioka H, Iwasaku M, et al. Successful treatment of non-small cell lung cancer with gefitinib after severe erlotinib-related hepatotoxicity. Intern Med 2012;51:431-4.

39. Sanford JP. Legionnaires' disease: one person's perspective. Ann Intern Med 1979;90:699-703.

40. Nora T, Lomma M, Gomez-Valero L, et al. Molecular mimicry: an important virulence strategy employed by Legionella pneumophila to subvert host functions. Future Microbiol 2009;4:691-701.

41. Gavrilovskaya I, Gorbunova E, Matthys V, et al. The Role of the Endothelium in HPS Pathogenesis and Potential Therapeutic Approaches. Adv Virol 2012;2012: 467059.

42. Summary of probable SARS cases with onset of illness from 1 November 2002 to 31 July 2003: World Health Organization. Available at: http://www.who.int/csr/ sars/country/table2004_04_21/en/index.html. Accessed December 17, 2012.

43. Gerlier D. Emerging zoonotic viruses: new lessons on receptor and entry mechanisms. Curr Opin Virol 2011;1:27-34.

44. Gordon CL, Holmes NE, Grayson ML, et al. Comparison of immunoglobulin G subclass concentrations in severe community-acquired pneumonia and severe pandemic 2009 influenza A (H1N1) infection. Clin Vaccine Immunol 2012;19:446-8.

45. Eisen DP, Stubbs J, Spilsbury D, et al. Low mannose-binding lectin complement activation function is associated with predisposition to Legionnaires' disease. Clin Exp Immunol 2007;149:97-102.

46. Sole-Violan J, Garcia-Laorden MI, Marcos-Ramos JA, et al. The Fcgamma receptor $\mathrm{IA}-\mathrm{H} / \mathrm{H} 131$ genotype is associated with bacteremia in pneumococcal community-acquired pneumonia. Crit Care Med 2011;39:1388-93.

47. Bautista E, Chotpitayasunondh T, Gao Z, et al. Clinical aspects of pandemic 2009 influenza A (H1N1) virus infection. N Engl J Med 2010;362:1708-19.

48. Everitt AR, Clare S, Pertel T, et al. IFITM3 restricts the morbidity and mortality associated with influenza. Nature 2012;484:519-23.

49. Wunderink RG, Waterer GW. Community-acquired pneumonia: pathophysiology and host factors with focus on possible new approaches to management of lower respiratory tract infections. Infect Dis Clin North Am 2004;18:743-59, vii. 
50. Mason CM, Nelson S. Pulmonary host defenses and factors predisposing to lung infection. Clin Chest Med 2005;26:11-7.

51. Shemer-Avni Y, Lieberman D. Chlamydia pneumoniae-induced ciliostasis in ciliated bronchial epithelial cells. J Infect Dis 1995;171:1274-8.

52. Liang $\mathrm{H}$, Jiang $\mathrm{W}$, Han $\mathrm{Q}$, et al. Ciliary ultrastructural abnormalities in Mycoplasma pneumoniae pneumonia in 22 pediatric patients. Eur J Pediatr 2012; 171:559-63.

53. Mitchell AM, Mitchell TJ. Streptococcus pneumoniae: virulence factors and variation. Clin Microbiol Infect 2010;16:411-8.

54. Bruggemann $\mathrm{H}$, Cazalet $\mathrm{C}$, Buchrieser $\mathrm{C}$. Adaptation of Legionella pneumophila to the host environment: role of protein secretion, effectors and eukaryotic-like proteins. Curr Opin Microbiol 2006;9:86-94.

55. Almirall J, Bolibar I, Balanzo X, et al. Risk factors for community-acquired pneumonia in adults: a population-based case-control study. Eur Respir J 1999;13: 349-55.

56. Laheij RJ, Sturkenboom MC, Hassing RJ, et al. Risk of community-acquired pneumonia and use of gastric acid-suppressive drugs. JAMA 2004;292:1955-60.

57. Gulmez SE, Holm A, Frederiksen $\mathrm{H}$, et al. Use of proton pump inhibitors and the risk of community-acquired pneumonia: a population-based case-control study. Arch Intern Med 2007;167:950-5.

58. Hermos JA, Young MM, Fonda JR, et al. Risk of community-acquired pneumonia in veteran patients to whom proton pump inhibitors were dispensed. Clin Infect Dis 2012;54:33-42.

59. Knol W, van Marum RJ, Jansen PA, et al. Antipsychotic drug use and risk of pneumonia in elderly people. J Am Geriatr Soc 2008;56:661-6.

60. Trifiro G, Gambassi G, Sen EF, et al. Association of community-acquired pneumonia with antipsychotic drug use in elderly patients: a nested case-control study. Ann Intern Med 2010;152:418-25, W139-440.

61. Almirall J, Bolibar I, Serra-Prat M, et al. Inhaled drugs as risk factors for community-acquired pneumonia. Eur Respir J 2010;36:1080-7.

62. Marrie TJ. Community-acquired pneumonia. Clin Infect Dis 1994;18:501-13 [quiz: 514-5].

63. Cilloniz C, Ewig S, Polverino E, et al. Microbial aetiology of community-acquired pneumonia and its relation to severity. Thorax 2011;66:340-6.

64. Restrepo MI, Mortensen EM, Velez JA, et al. A comparative study of communityacquired pneumonia patients admitted to the ward and the ICU. Chest 2008; 133:610-7.

65. Marrie TJ, Shariatzadeh MR. Community-acquired pneumonia requiring admission to an intensive care unit: a descriptive study. Medicine (Baltimore) 2007;86: 103-11.

66. Martin-Loeches I, Lisboa T, Rodriguez A, et al. Combination antibiotic therapy with macrolides improves survival in intubated patients with communityacquired pneumonia. Intensive Care Med 2010;36:612-20.

67. Rodriguez A, Mendia A, Sirvent JM, et al. Combination antibiotic therapy improves survival in patients with community-acquired pneumonia and shock. Crit Care Med 2007;35:1493-8.

68. Hageman JC, Uyeki TM, Francis JS, et al. Severe community-acquired pneumonia due to Staphylococcus aureus, 2003-04 influenza season. Emerg Infect Dis 2006;12:894-9.

69. Centers for Disease Control and Prevention (CDC). Severe methicillin-resistant Staphylococcus aureus community-acquired pneumonia associated with 
influenza-Louisiana and Georgia, December 2006-January 2007. MMWR Morb Mortal Wkly Rep 2007;56:325-9.

70. Kallen AJ, Brunkard J, Moore Z, et al. Staphylococcus aureus communityacquired pneumonia during the 2006 to 2007 influenza season. Ann Emerg Med 2009;53:358-65.

71. Arancibia F, Bauer TT, Ewig S, et al. Community-acquired pneumonia due to gram-negative bacteria and pseudomonas aeruginosa: incidence, risk, and prognosis. Arch Intern Med 2002;162:1849-58.

72. Johansson N, Kalin M, Tiveljung-Lindell A, et al. Etiology of community-acquired pneumonia: increased microbiological yield with new diagnostic methods. Clin Infect Dis 2010;50:202-9.

73. Shibli F, Chazan B, Nitzan O, et al. Etiology of community-acquired pneumonia in hospitalized patients in northern Israel. Isr Med Assoc J 2010;12:477-82.

74. Appelbaum PC, Bhamjee A, Scragg JN, et al. Streptococcus pneumoniae resistant to penicillin and chloramphenicol. Lancet 1977;2:995-7.

75. Hoban DJ, Doern GV, Fluit AC, et al. Worldwide prevalence of antimicrobial resistance in Streptococcus pneumoniae, Haemophilus influenzae, and Moraxella catarrhalis in the SENTRY Antimicrobial Surveillance Program, 1997-1999. Clin Infect Dis 2001;32(Suppl 2):S81-93.

76. Jacobs MR, Good CE, Windau AR, et al. Activity of ceftaroline against recent emerging serotypes of Streptococcus pneumoniae in the United States. Antimicrob Agents Chemother 2010;54:2716-9.

77. Moroney JF, Fiore AE, Harrison LH, et al. Clinical outcomes of bacteremic pneumococcal pneumonia in the era of antibiotic resistance. Clin Infect Dis 2001;33: 797-805.

78. Yu VL, Chiou CC, Feldman C, et al. An international prospective study of pneumococcal bacteremia: correlation with in vitro resistance, antibiotics administered, and clinical outcome. Clin Infect Dis 2003;37:230-7.

79. Feikin DR, Schuchat A, Kolczak M, et al. Mortality from invasive pneumococcal pneumonia in the era of antibiotic resistance, 1995-1997. Am J Public Health 2000;90:223-9.

80. Turett GS, Blum S, Fazal BA, et al. Penicillin resistance and other predictors of mortality in pneumococcal bacteremia in a population with high human immunodeficiency virus seroprevalence. Clin Infect Dis 1999;29:321-7.

81. Klugman KP. Bacteriological evidence of antibiotic failure in pneumococcal lower respiratory tract infections. Eur Respir J Suppl 2002;36:3s-8s.

82. Doern GV, Richter SS, Miller A, et al. Antimicrobial resistance among Streptococcus pneumoniae in the United States: have we begun to turn the corner on resistance to certain antimicrobial classes? Clin Infect Dis 2005;41:139-48.

83. Daneman N, McGeer A, Green K, et al. Macrolide resistance in bacteremic pneumococcal disease: implications for patient management. Clin Infect Dis 2006;43:432-8.

84. Feldman RB, Rhew DC, Wong JY, et al. Azithromycin monotherapy for patients hospitalized with community-acquired pneumonia: a 31/2-year experience from a veterans affairs hospital. Arch Intern Med 2003;163:1718-26.

85. Patel SN, McGeer A, Melano R, et al. Susceptibility of Streptococcus pneumoniae to fluoroquinolones in Canada. Antimicrob Agents Chemother 2011;55: 3703-8.

86. Thornsberry C, Brown NP, Draghi DC, et al. Antimicrobial activity among multidrug-resistant Streptococcus pneumoniae isolated in the United States, 2001-2005. Postgrad Med 2008;120:32-8. 
87. Vanderkooi OG, Low DE, Green K, et al. Predicting antimicrobial resistance in invasive pneumococcal infections. Clin Infect Dis 2005;40:1288-97.

88. Barber M. Methicillin-resistant staphylococci. J Clin Pathol 1961;14:385-93.

89. Benner EJ, Kayser FH. Growing clinical significance of methcillin-resistant Staphylococcus aureus. Lancet 1968;2:741-4.

90. National Nosocomial Infections Surveillance System. National Nosocomial Infections Surveillance (NNIS) System Report, data summary from January 1992 through June 2004, issued October 2004. Am J Infect Control 2004;32:470-85.

91. Rubinstein E, Kollef MH, Nathwani D. Pneumonia caused by methicillin-resistant Staphylococcus aureus. Clin Infect Dis 2008;46(Suppl 5):S378-85.

92. Li M, Diep BA, Villaruz AE, et al. Evolution of virulence in epidemic communityassociated methicillin-resistant Staphylococcus aureus. Proc Natl Acad Sci U S A 2009;106:5883-8.

93. Labandeira-Rey M, Couzon F, Boisset S, et al. Staphylococcus aureus Panton-Valentine leukocidin causes necrotizing pneumonia. Science 2007; 315:1130-3.

94. Gillet Y, Issartel B, Vanhems P, et al. Association between Staphylococcus aureus strains carrying gene for Panton-Valentine leukocidin and highly lethal necrotising pneumonia in young immunocompetent patients. Lancet 2002; 359:753-9.

95. Francis JS, Doherty MC, Lopatin U, et al. Severe community-onset pneumonia in healthy adults caused by methicillin-resistant Staphylococcus aureus carrying the Panton-Valentine leukocidin genes. Clin Infect Dis 2005;40:100-7.

96. Hidron Al, Low CE, Honig EG, et al. Emergence of community-acquired meticillin-resistant Staphylococcus aureus strain USA300 as a cause of necrotising community-onset pneumonia. Lancet Infect Dis 2009;9:384-92.

97. Vardakas KZ, Matthaiou DK, Falagas ME. Incidence, characteristics and outcomes of patients with severe community acquired-MRSA pneumonia. Eur Respir J 2009;34:1148-58.

98. van der Flier M, van Dijk NB, Fluit AC, et al. Fatal pneumonia in an adolescent due to community-acquired methicillin-resistant Staphylococcus aureus positive for Panton-Valentine-leukocidin. Ned Tijdschr Geneeskd 2003;147:1076-9 [in Dutch].

99. Castaldo ET, Yang EY. Severe sepsis attributable to community-associated methicillin-resistant Staphylococcus aureus: an emerging fatal problem. Am Surg 2007;73:684-7 [discussion: 687-8].

100. Molinari NA, Ortega-Sanchez IR, Messonnier ML, et al. The annual impact of seasonal influenza in the US: measuring disease burden and costs. Vaccine 2007;25:5086-96.

101. Shrestha SS, Swerdlow DL, Borse RH, et al. Estimating the burden of 2009 pandemic influenza A (H1N1) in the United States (April 2009-April 2010). Clin Infect Dis 2011;52(Suppl 1):S75-82.

102. Lum ME, McMillan AJ, Brook CW, et al. Impact of pandemic (H1N1) 2009 influenza on critical care capacity in Victoria. Med J Aust 2009;191:502-6.

103. Kumar A, Zarychanski R, Pinto R, et al. Critically ill patients with 2009 influenza $\mathrm{A}(\mathrm{H} 1 \mathrm{N1})$ infection in Canada. JAMA 2009;302:1872-9.

104. Briand S, Fukuda K. Avian influenza A (H5N1) virus and 2 fundamental questions. J Infect Dis 2009;199:1717-9.

105. Stephenson I, Democratis J. Influenza: current threat from avian influenza. $\mathrm{Br}$ Med Bull 2005;75-76:63-80. 
106. Yuen KY, Chan PK, Peiris M, et al. Clinical features and rapid viral diagnosis of human disease associated with avian influenza A H5N1 virus. Lancet 1998;351: 467-71.

107. Katz JM, Lim W, Bridges CB, et al. Antibody response in individuals infected with avian influenza A (H5N1) viruses and detection of anti-H5 antibody among household and social contacts. J Infect Dis 1999;180:1763-70.

108. Corman V, Eckerle I, Bleicker T, et al. Detection of a novel human coronavirus by real-time reverse-transcription polymerase chain reaction. Euro Surveill 2012;17. pii:20285.

109. Danielsson N, On Behalf Of The Ecdc Internal Response Team, Catchpole M. Novel coronavirus associated with severe respiratory disease: case definition and public health measures. Euro Surveill 2012;17. pii:20282.

110. Coronavirus Infections: World Health Organization. 2012. Available at: http://www. who.int/csr/disease/coronavirus_infections/en/index.html. Accessed December 19, 2012.

111. Bartlett JG, Dowell SF, Mandell LA, et al. Practice guidelines for the management of community-acquired pneumonia in adults. Infectious Diseases Society of America. Clin Infect Dis 2000;31:347-82.

112. Metlay JP, Kapoor WN, Fine MJ. Does this patient have community-acquired pneumonia? Diagnosing pneumonia by history and physical examination. JAMA 1997;278:1440-5.

113. Kushner I. The phenomenon of the acute phase response. Ann N Y Acad Sci 1982;389:39-48.

114. Morley JJ, Kushner I. Serum C-reactive protein levels in disease. Ann N Y Acad Sci 1982;389:406-18.

115. Vanderschueren S, Deeren D, Knockaert DC, et al. Extremely elevated C-reactive protein. Eur J Intern Med 2006;17:430-3.

116. Le Gall C, Desideri-Vaillant C, Nicolas X. Significations of extremely elevated C-reactive protein: about 91 cases in a French hospital center. Pathol Biol (Paris) 2011;59:319-20 [in French].

117. Flanders SA, Stein J, Shochat G, et al. Performance of a bedside C-reactive protein test in the diagnosis of community-acquired pneumonia in adults with acute cough. Am J Med 2004;116:529-35.

118. Holm A, Nexoe J, Bistrup LA, et al. Aetiology and prediction of pneumonia in lower respiratory tract infection in primary care. Br J Gen Pract 2007;57: 547-54.

119. Almirall J, Bolibar I, Toran P, et al. Contribution of C-reactive protein to the diagnosis and assessment of severity of community-acquired pneumonia. Chest 2004; 125:1335-42.

120. Kruger S, Ewig S, Papassotiriou J, et al. Inflammatory parameters predict etiologic patterns but do not allow for individual prediction of etiology in patients with CAP: results from the German competence network CAPNETZ. Respir Res 2009;10:65.

121. Simon L, Gauvin F, Amre DK, et al. Serum procalcitonin and C-reactive protein levels as markers of bacterial infection: a systematic review and meta-analysis. Clin Infect Dis 2004;39:206-17.

122. Boussekey N, Leroy $\mathrm{O}$, Alfandari S, et al. Procalcitonin kinetics in the prognosis of severe community-acquired pneumonia. Intensive Care Med 2006;32:469-72.

123. Christ-Crain M, Jaccard-Stolz D, Bingisser $R$, et al. Effect of procalcitoninguided treatment on antibiotic use and outcome in lower respiratory tract 
infections: cluster-randomised, single-blinded intervention trial. Lancet 2004; 363:600-7.

124. Christ-Crain M, Stolz D, Bingisser R, et al. Procalcitonin guidance of antibiotic therapy in community-acquired pneumonia: a randomized trial. Am J Respir Crit Care Med 2006;174:84-93.

125. Schuetz P, Christ-Crain M, Thomann R, et al. Effect of procalcitonin-based guidelines vs standard guidelines on antibiotic use in lower respiratory tract infections: the ProHOSP randomized controlled trial. JAMA 2009;302:1059-66.

126. Masia M, Gutierrez F, Shum C, et al. Usefulness of procalcitonin levels in community-acquired pneumonia according to the patients outcome research team pneumonia severity index. Chest 2005;128:2223-9.

127. Muller F, Christ-Crain M, Bregenzer T, et al. Procalcitonin levels predict bacteremia in patients with community-acquired pneumonia: a prospective cohort trial. Chest 2010;138:121-9.

128. Pugh R, Grant C, Cooke RP, et al. Short-course versus prolonged-course antibiotic therapy for hospital-acquired pneumonia in critically ill adults. Cochrane Database Syst Rev 2011;(10):CD007577.

129. Mayo JR, Aldrich J, Muller NL. Radiation exposure at chest CT: a statement of the Fleischner Society. Radiology 2003;228:15-21.

130. Corbo J, Friedman B, Bijur P, et al. Limited usefulness of initial blood cultures in community acquired pneumonia. Emerg Med J 2004;21:446-8.

131. Murray PR, Washington JA. Microscopic and baceriologic analysis of expectorated sputum. Mayo Clin Proc 1975;50:339-44.

132. Bartlett JG, Finegold SM. Bacteriology of expectorated sputum with quantitative culture and wash technique compared to transtracheal aspirates. Am Rev Respir Dis 1978;117:1019-27.

133. Jimenez P, Saldias F, Meneses M, et al. Diagnostic fiberoptic bronchoscopy in patients with community-acquired pneumonia. Comparison between bronchoalveolar lavage and telescoping plugged catheter cultures. Chest 1993;103:1023-7.

134. Wimberley N, Faling LJ, Bartlett JG. A fiberoptic bronchoscopy technique to obtain uncontaminated lower airway secretions for bacterial culture. Am Rev Respir Dis 1979;119:337-43.

135. Sorde R, Falco V, Lowak M, et al. Current and potential usefulness of pneumococcal urinary antigen detection in hospitalized patients with communityacquired pneumonia to guide antimicrobial therapy. Arch Intern Med 2011; 171:166-72.

136. Smith MD, Derrington $P$, Evans $R$, et al. Rapid diagnosis of bacteremic pneumococcal infections in adults by using the Binax NOW Streptococcus pneumoniae urinary antigen test: a prospective, controlled clinical evaluation. J Clin Microbiol 2003;41:2810-3.

137. Helbig JH, Uldum SA, Bernander S, et al. Clinical utility of urinary antigen detection for diagnosis of community-acquired, travel-associated, and nosocomial legionnaires' disease. J Clin Microbiol 2003;41:838-40.

138. Yu VL, Plouffe JF, Pastoris MC, et al. Distribution of Legionella species and serogroups isolated by culture in patients with sporadic community-acquired legionellosis: an international collaborative survey. J Infect Dis 2002;186:127-8.

139. Fine MJ, Auble TE, Yealy DM, et al. A prediction rule to identify low-risk patients with community-acquired pneumonia. N Engl J Med 1997;336:243-50.

140. Lim WS, van der Eerden MM, Laing R, et al. Defining community acquired pneumonia severity on presentation to hospital: an international derivation and validation study. Thorax 2003;58:377-82. 
141. Niederman MS, Feldman C, Richards GA. Combining information from prognostic scoring tools for CAP: an American view on how to get the best of all worlds. Eur Respir J 2006;27:9-11.

142. Niederman MS. Recent advances in community-acquired pneumonia: inpatient and outpatient. Chest 2007;131:1205-15.

143. Kontou P, Kuti JL, Nicolau DP. Validation of the Infectious Diseases Society of America/American Thoracic Society criteria to predict severe communityacquired pneumonia caused by Streptococcus pneumoniae. Am J Emerg Med 2009;27:968-74.

144. Phua J, See KC, Chan YH, et al. Validation and clinical implications of the IDSA/ ATS minor criteria for severe community-acquired pneumonia. Thorax 2009;64: 598-603.

145. Chalmers JD, Taylor JK, Mandal P, et al. Validation of the Infectious Diseases Society of America/American Thoratic Society minor criteria for intensive care unit admission in community-acquired pneumonia patients without major criteria or contraindications to intensive care unit care. Clin Infect Dis 2011;53:503-11.

146. Liapikou A, Ferrer M, Polverino E, et al. Severe community-acquired pneumonia: validation of the Infectious Diseases Society of America/American Thoracic Society guidelines to predict an intensive care unit admission. Clin Infect Dis 2009;48:377-85.

147. Charles PG, Wolfe R, Whitby M, et al. SMART-COP: a tool for predicting the need for intensive respiratory or vasopressor support in community-acquired pneumonia. Clin Infect Dis 2008;47:375-84.

148. Rello J, Rodriguez A, Lisboa T, et al. PIRO score for community-acquired pneumonia: a new prediction rule for assessment of severity in intensive care unit patients with community-acquired pneumonia. Crit Care Med 2009;37:456-62.

149. Knaus WA, Draper EA, Wagner DP, et al. APACHE II: a severity of disease classification system. Crit Care Med 1985;13:818-29.

150. Le Gall JR, Lemeshow S, Saulnier F. A new Simplified Acute Physiology Score (SAPS II) based on a European/North American multicenter study. JAMA 1993;270:2957-63.

151. Lim WS, Baudouin SV, George RC, et al. BTS guidelines for the management of community acquired pneumonia in adults: update 2009. Thorax 2009; 64(Suppl 3):iii1-55.

152. Park M, Markus P, Matesic D, et al. Safety and effectiveness of a preoperative allergy clinic in decreasing vancomycin use in patients with a history of penicillin allergy. Ann Allergy Asthma Immunol 2006;97:681-7.

153. Gadde J, Spence M, Wheeler B, et al. Clinical experience with penicillin skin testing in a large inner-city STD clinic. JAMA 1993;270:2456-63.

154. Jost BC, Wedner HJ, Bloomberg GR. Elective penicillin skin testing in a pediatric outpatient setting. Ann Allergy Asthma Immunol 2006;97:807-12.

155. Macy E, Schatz M, Lin C, et al. The falling rate of positive penicillin skin tests from 1995 to 2007. Perm J 2009;13:12-8.

156. Atanaskovic-Markovic M, Gaeta F, Medjo B, et al. Tolerability of meropenem in children with IgE-mediated hypersensitivity to penicillins. Allergy 2008;63: 237-40.

157. Romano A, Viola M, Gueant-Rodriguez RM, et al. Imipenem in patients with immediate hypersensitivity to penicillins. N Engl J Med 2006;354:2835-7.

158. Atanaskovic-Markovic M, Velickovic TC, Gavrovic-Jankulovic M, et al. Immediate allergic reactions to cephalosporins and penicillins and their crossreactivity in children. Pediatr Allergy Immunol 2005;16:341-7. 
159. Wunderink RG, Niederman MS, Kollef MH, et al. Linezolid in methicillin-resistant Staphylococcus aureus nosocomial pneumonia: a randomized, controlled study. Clin Infect Dis 2012;54:621-9.

160. Dumitrescu O, Boisset S, Badiou C, et al. Effect of antibiotics on Staphylococcus aureus producing Panton-Valentine leukocidin. Antimicrob Agents Chemother 2007;51:1515-9.

161. Dumitrescu O, Badiou C, Bes M, et al. Effect of antibiotics, alone and in combination, on Panton-Valentine leukocidin production by a Staphylococcus aureus reference strain. Clin Microbiol Infect 2008;14:384-8.

162. Bernardo K, Pakulat N, Fleer S, et al. Subinhibitory concentrations of linezolid reduce Staphylococcus aureus virulence factor expression. Antimicrob Agents Chemother 2004;48:546-55.

163. Lodise TP, Graves J, Evans A, et al. Relationship between vancomycin MIC and failure among patients with methicillin-resistant Staphylococcus aureus bacteremia treated with vancomycin. Antimicrob Agents Chemother 2008;52: 3315-20.

164. Soriano A, Marco F, Martinez JA, et al. Influence of vancomycin minimum inhibitory concentration on the treatment of methicillin-resistant Staphylococcus aureus bacteremia. Clin Infect Dis 2008;46:193-200.

165. van Hal SJ, Lodise TP, Paterson DL. The clinical significance of vancomycin minimum inhibitory concentration in Staphylococcus aureus infections: a systematic review and meta-analysis. Clin Infect Dis 2012;54:755-71.

166. FDA Drug Safety Communication: Increase risk of death with Tygacil (tigecycline) compared to other antibiotics used to treat similar infections: U.S. Food and Drug Administration. 2010. Available at: http://www.fda.gov/Drugs/ DrugSafety/ucm224370.htm\#aihp. Accessed December 18, 2012.

167. Prasad P, Sun J, Danner RL, et al. Excess deaths associated with tigecycline after approval based on noninferiority trials. Clin Infect Dis 2012;54:1699-709.

168. Fiore AE, Fry A, Shay D, et al. Antiviral agents for the treatment and chemoprophylaxis of influenza - recommendations of the Advisory Committee on Immunization Practices (ACIP). MMWR Recomm Rep 2011;60:1-24.

169. Kiatboonsri S, Kiatboonsri C, Theerawit P. Fatal respiratory events caused by zanamivir nebulization. Clin Infect Dis 2010;50:620.

170. Nicholson KG, Aoki FY, Osterhaus AD, et al. Efficacy and safety of oseltamivir in treatment of acute influenza: a randomised controlled trial. Neuraminidase Inhibitor Flu Treatment Investigator Group. Lancet 2000;355:1845-50.

171. Kaiser L, Wat C, Mills $T$, et al. Impact of oseltamivir treatment on influenzarelated lower respiratory tract complications and hospitalizations. Arch Intern Med 2003;163:1667-72.

172. Jefferson T, Demicheli V, Rivetti D, et al. Antivirals for influenza in healthy adults: systematic review. Lancet 2006;367:303-13.

173. Rodriguez A, Diaz E, Martin-Loeches I, et al. Impact of early oseltamivir treatment on outcome in critically ill patients with 2009 pandemic influenza A. J Antimicrob Chemother 2011;66:1140-9.

174. Kumar A. Early versus late oseltamivir treatment in severely ill patients with 2009 pandemic influenza $A(H 1 N 1)$ : speed is life. J Antimicrob Chemother 2011;66: 959-63.

175. Louie JK, Yang S, Acosta M, et al. Treatment With Neuraminidase Inhibitors for Critically III Patients With Influenza A (H1N1)pdm09. Clin Infect Dis 2012;55: 1198-204. 
176. Ling LM, Chow AL, Lye DC, et al. Effects of early oseltamivir therapy on viral shedding in 2009 pandemic influenza $A(H 1 N 1)$ virus infection. Clin Infect Dis 2010;50:963-9.

177. Zhang G, Xia Z, Liu Y, et al. Epidemiological and clinical features of 308 hospitalized patients with novel 2009 influenza A (H1N1) virus infection in China during the first pandemic wave. Intervirology 2011;54:164-70.

178. Updated interim recommendations for the use of antiviral medications in the treatment and prevention of influenza for the 2009-2010 season: United States Centers for Disease Control and Prevention. Available at: http://www.cdc.gov/ h1n1flu/recommendations.htm. Accessed December 18, 2012.

179. Taylor WR, Thinh BN, Anh GT, et al. Oseltamivir is adequately absorbed following nasogastric administration to adult patients with severe H5N1 influenza. PLoS One 2008;3:e3410.

180. Ariano RE, Sitar DS, Zelenitsky SA, et al. Enteric absorption and pharmacokinetics of oseltamivir in critically ill patients with pandemic (H1N1) influenza. CMAJ 2010;182:357-63.

181. US Centers for Disease Control and Prevention. Prevention Strategies for Seasonal Influenza in Healthcare Settings. http://www.cdc.gov/flu/professionals/ infectioncontrol/healthcaresettings.htm. Accessed November 14, 2012.

182. Parnham MJ. Immunomodulatory effects of antimicrobials in the therapy of respiratory tract infections. Curr Opin Infect Dis 2005;18:125-31.

183. Giamarellos-Bourboulis EJ. Immunomodulatory therapies for sepsis: unexpected effects with macrolides. Int J Antimicrob Agents 2008;32(Suppl 1): S39-43.

184. Simpson JL, Powell H, Boyle MJ, et al. Clarithromycin targets neutrophilic airway inflammation in refractory asthma. Am J Respir Crit Care Med 2008; 177:148-55.

185. Albert RK, Connett J, Bailey WC, et al. Azithromycin for prevention of exacerbations of COPD. N Engl J Med 2011;365:689-98.

186. Schultz MJ. Macrolide activities beyond their antimicrobial effects: macrolides in diffuse panbronchiolitis and cystic fibrosis. J Antimicrob Chemother 2004;54: 21-8.

187. Baddour LM, Yu VL, Klugman KP, et al. Combination antibiotic therapy lowers mortality among severely ill patients with pneumococcal bacteremia. Am J Respir Crit Care Med 2004;170:440-4.

188. Restrepo MI, Mortensen EM, Waterer GW, et al. Impact of macrolide therapy on mortality for patients with severe sepsis due to pneumonia. Eur Respir J 2009; 33:153-9.

189. Ray WA, Murray KT, Hall K, et al. Azithromycin and the risk of cardiovascular death. N Engl J Med 2012;366:1881-90.

190. Baudel JL, Tankovic J, Carrat F, et al. Does nonadherence to local recommendations for empirical antibiotic therapy on admission to the intensive care unit have an impact on in-hospital mortality? Ther Clin Risk Manag 2009;5:491-8.

191. Frei CR, Attridge RT, Mortensen EM, et al. Guideline-concordant antibiotic use and survival among patients with community-acquired pneumonia admitted to the intensive care unit. Clin Ther 2010;32:293-9.

192. Asadi L, Sligl WI, Eurich DT, et al. Macrolide-Based Regimens and Mortality in Hospitalized Patients With Community-Acquired Pneumonia: a Systematic Review and Meta-analysis. Clin Infect Dis 2012;55:371-80. 
193. Mortensen EM, Restrepo M, Anzueto A, et al. Effects of guideline-concordant antimicrobial therapy on mortality among patients with community-acquired pneumonia. Am J Med 2004;117:726-31.

194. Menendez R, Torres A, Zalacain R, et al. Guidelines for the treatment of community-acquired pneumonia: predictors of adherence and outcome. Am J Respir Crit Care Med 2005;172:757-62.

195. McCabe C, Kirchner C, Zhang H, et al. Guideline-concordant therapy and reduced mortality and length of stay in adults with community-acquired pneumonia: playing by the rules. Arch Intern Med 2009;169:1525-31.

196. Kumar A, Ellis $P$, Arabi $Y$, et al. Initiation of inappropriate antimicrobial therapy results in a fivefold reduction of survival in human septic shock. Chest 2009; 136:1237-48.

197. Kumar A, Roberts D, Wood KE, et al. Duration of hypotension before initiation of effective antimicrobial therapy is the critical determinant of survival in human septic shock. Crit Care Med 2006;34:1589-96.

198. Hoang H, Sligl WI, Eurich DT, et al. Macrolide use in the treatment of critically ill patients with pneumonia; incidence, correlates, timing, and outcomes. Can J Infect Dis Med Microbiol 2012;23(Suppl):B 24.

199. Houck PM, Bratzler DW, Nsa W, et al. Timing of antibiotic administration and outcomes for Medicare patients hospitalized with community-acquired pneumonia. Arch Intern Med 2004;164:637-44.

200. Mertz D, Koller M, Haller P, et al. Outcomes of early switching from intravenous to oral antibiotics on medical wards. J Antimicrob Chemother 2009;64:188-99.

201. Oosterheert JJ, Bonten MJ, Schneider MM, et al. Effectiveness of early switch from intravenous to oral antibiotics in severe community acquired pneumonia: multicentre randomised trial. BMJ 2006;333:1193.

202. van der Eerden MM, de Graaff CS, Vlaspolder F, et al. Evaluation of an algorithm for switching from IV to PO therapy in clinical practice in patients with community-acquired pneumonia. Clin Ther 2004;26:294-303.

203. Menendez R, Torres A, Zalacain R, et al. Risk factors of treatment failure in community acquired pneumonia: implications for disease outcome. Thorax 2004;59: 960-5.

204. Roson B, Carratala J, Fernandez-Sabe N, et al. Causes and factors associated with early failure in hospitalized patients with community-acquired pneumonia. Arch Intern Med 2004;164:502-8.

205. Arancibia F, Ewig S, Martinez JA, et al. Antimicrobial treatment failures in patients with community-acquired pneumonia: causes and prognostic implications. Am J Respir Crit Care Med 2000;162:154-60.

206. Li JZ, Winston LG, Moore DH, et al. Efficacy of short-course antibiotic regimens for community-acquired pneumonia: a meta-analysis. Am J Med 2007;120:783-90.

207. Liu C, Bayer A, Cosgrove SE, et al. Clinical practice guidelines by the infectious diseases society of america for the treatment of methicillin-resistant Staphylococcus aureus infections in adults and children. Clin Infect Dis 2011;52:e18-55.

208. Hayashi Y, Paterson DL. Strategies for reduction in duration of antibiotic use in hospitalized patients. Clin Infect Dis 2011;52:1232-40.

209. Avdic E, Cushinotto LA, Hughes AH, et al. Impact of an antimicrobial stewardship intervention on shortening the duration of therapy for community-acquired pneumonia. Clin Infect Dis 2012;54:1581-7.

210. Agarwal R, Aggarwal AN, Gupta D, et al. Etiology and outcomes of pulmonary and extrapulmonary acute lung injury/ARDS in a respiratory ICU in North India. Chest 2006;130:724-9. 
211. Irish Critical Care Trials Group. Acute lung injury and the acute respiratory distress syndrome in Ireland: a prospective audit of epidemiology and management. Crit Care 2008;12:R30.

212. Ventilation with lower tidal volumes as compared with traditional tidal volumes for acute lung injury and the acute respiratory distress syndrome. The Acute Respiratory Distress Syndrome Network. N Engl J Med 2000;342:1301-8.

213. Rivers E, Nguyen B, Havstad S, et al. Early goal-directed therapy in the treatment of severe sepsis and septic shock. N Engl J Med 2001;345:1368-77.

214. Sprung CL, Annane D, Keh D, et al. Hydrocortisone therapy for patients with septic shock. N Engl J Med 2008;358:111-24.

215. Annane D, Sebille V, Charpentier C, et al. Effect of treatment with low doses of hydrocortisone and fludrocortisone on mortality in patients with septic shock. JAMA 2002;288:862-71.

216. Annane D, Bellissant E, Bollaert PE, et al. Corticosteroids for treating severe sepsis and septic shock. Cochrane Database Syst Rev 2004;(1):CD002243.

217. Sligl WI, Milner DA Jr, Sundar S, et al. Safety and efficacy of corticosteroids for the treatment of septic shock: a systematic review and meta-analysis. Clin Infect Dis 2009;49:93-101.

218. Confalonieri M, Urbino R, Potena A, et al. Hydrocortisone infusion for severe community-acquired pneumonia: a preliminary randomized study. Am J Respir Crit Care Med 2005;171:242-8.

219. Garcia-Vidal C, Calbo E, Pascual V, et al. Effects of systemic steroids in patients with severe community-acquired pneumonia. Eur Respir J 2007;30:951-6.

220. Snijders D, Daniels JM, de Graaff CS, et al. Efficacy of corticosteroids in community-acquired pneumonia: a randomized double-blinded clinical trial. Am J Respir Crit Care Med 2010;181:975-82.

221. Meijvis SC, Hardeman $\mathrm{H}$, Remmelts $\mathrm{HH}$, et al. Dexamethasone and length of hospital stay in patients with community-acquired pneumonia: a randomised, double-blind, placebo-controlled trial. Lancet 2011;377:2023-30.

222. Meduri GU, Bell WA, Confalonieri M. Glucocorticoid treatment in communityacquired pneumonia without severe sepsis: no evidence of efficacy. Am J Respir Crit Care Med 2010;181:880-2.

223. Peek GJ, Mugford M, Tiruvoipati R, et al. Efficacy and economic assessment of conventional ventilatory support versus extracorporeal membrane oxygenation for severe adult respiratory failure (CESAR): a multicentre randomised controlled trial. Lancet 2009;374:1351-63.

224. Noah MA, Peek GJ, Finney SJ, et al. Referral to an extracorporeal membrane oxygenation center and mortality among patients with severe 2009 influenza A(H1N1). JAMA 2011;306:1659-68.

225. Centers for Disease Control and Prevention (CDC). Smoking-attributable mortality, years of potential life lost, and productivity losses-United States, 2000-2004. MMWR Morb Mortal Wkly Rep 2008;57:1226-8.

226. Stead LF, Lancaster T. Combined pharmacotherapy and behavioural interventions for smoking cessation. Cochrane Database Syst Rev 2012;(10):CD008286.

227. Musher DM, Manof SB, Liss C, et al. Safety and antibody response, including antibody persistence for 5 years, after primary vaccination or revaccination with pneumococcal polysaccharide vaccine in middle-aged and older adults. $J$ Infect Dis 2010;201:516-24.

228. Manoff SB, Liss C, Caulfield MJ, et al. Revaccination with a 23-valent pneumococcal polysaccharide vaccine induces elevated and persistent functional antibody responses in adults aged 65 > or = years. J Infect Dis 2010;201:525-33. 
229. Shapiro ED, Berg AT, Austrian R, et al. The protective efficacy of polyvalent pneumococcal polysaccharide vaccine. N Engl J Med 1991;325:1453-60.

230. Moberley SA, Holden J, Tatham DP, et al. Vaccines for preventing pneumococcal infection in adults. Cochrane Database Syst Rev 2008;(1):CD000422.

231. Centers for Disease Control and Prevention (CDC), Advisory Committee on Immunization Practices. Updated recommendations for prevention of invasive pneumococcal disease among adults using the 23-valent pneumococcal polysaccharide vaccine (PPSV23). MMWR Morb Mortal Wkly Rep 2010;59:1102-6.

232. Centers for Disease Control and Prevention (CDC). Use of 13-Valent Pneumococcal Conjugate Vaccine and 23-Valent Pneumococcal Polysaccharide Vaccine for Adults with Immunocompromising Conditions: recommendations of the Advisory Committee on Immunization Practices (ACIP). MMWR Morb Mortal Wkly Rep 2012;61:816-9.

233. Centers for Disease Control and Prevention (CDC). Prevention and control of influenza with vaccines: recommendations of the Advisory Committee on Immunization Practices (ACIP)-United States, 2012-13 influenza season. MMWR Morb Mortal Wkly Rep 2012;61:613-8.

234. Fine MJ, Smith MA, Carson CA, et al. Prognosis and outcomes of patients with community-acquired pneumonia. A meta-analysis. JAMA 1996;275:134-41.

235. Cabre M, Serra-Prat M, Force L, et al. Functional status as a risk factor for mortality in very elderly patients with pneumonia. Med Clin (Barc) 2008;131:167-70.

236. Mody L, Sun R, Bradley SF. Assessment of pneumonia in older adults: effect of functional status. J Am Geriatr Soc 2006;54:1062-7.

237. Torres $\mathrm{OH}$, Munoz J, Ruiz D, et al. Outcome predictors of pneumonia in elderly patients: importance of functional assessment. J Am Geriatr Soc 2004;52: 1603-9.

238. Davis RB, lezzoni LI, Phillips RS, et al. Predicting in-hospital mortality. The importance of functional status information. Med Care 1995;33:906-21.

239. Metersky ML, Waterer G, Nsa W, et al. Predictors of in-hospital vs postdischarge mortality in pneumonia. Chest 2012;142:476-81.

240. Aspa J, Rajas O, Rodriguez de Castro F, et al. Impact of initial antibiotic choice on mortality from pneumococcal pneumonia. Eur Respir J 2006;27:1010-9.

241. Menendez R, Torres A, Reyes S, et al. Initial management of pneumonia and sepsis: factors associated with improved outcome. Eur Respir J 2012;39: 156-62.

242. Marshall JC, Cook DJ, Christou NV, et al. Multiple organ dysfunction score: a reliable descriptor of a complex clinical outcome. Crit Care Med 1995;23: 1638-52.

243. Vincent JL, de Mendonca A, Cantraine F, et al. Use of the SOFA score to assess the incidence of organ dysfunction/failure in intensive care units: results of a multicenter, prospective study. Working group on "sepsis-related problems" of the European Society of Intensive Care Medicine. Crit Care Med 1998;26: 1793-800.

244. Seneff MG, Zimmerman JE, Knaus WA, et al. Predicting the duration of mechanical ventilation. The importance of disease and patient characteristics. Chest 1996;110:469-79.

245. Scheinhorn DJ, Hassenpflug MS, Votto JJ, et al. Post-ICU mechanical ventilation at 23 long-term care hospitals: a multicenter outcomes study. Chest 2007;131: 85-93.

246. Bigatello LM, Stelfox HT, Berra L, et al. Outcome of patients undergoing prolonged mechanical ventilation after critical illness. Crit Care Med 2007;35:2491-7. 
247. Viasus D, Garcia-Vidal C, Manresa F, et al. Risk stratification and prognosis of acute cardiac events in hospitalized adults with community-acquired pneumonia. J Infect 2013;66:27-33.

248. Corrales-Medina VF, Suh KN, Rose G, et al. Cardiac complications in patients with community-acquired pneumonia: a systematic review and meta-analysis of observational studies. PLoS Med 2011;8:e1001048.

249. Corrales-Medina VF, Musher DM, Wells GA, et al. Cardiac complications in patients with community-acquired pneumonia: incidence, timing, risk factors, and association with short-term mortality. Circulation 2012;125:773-81.

250. Leroy O, Santre C, Beuscart C, et al. A five-year study of severe communityacquired pneumonia with emphasis on prognosis in patients admitted to an intensive care unit. Intensive Care Med 1995;21:24-31.

251. Brown SM, Jones JP, Aronsky D, et al. Relationships among initial hospital triage, disease progression and mortality in community-acquired pneumonia. Respirology 2012;17:1207-13.

252. Ewig S, de Roux A, Bauer T, et al. Validation of predictive rules and indices of severity for community acquired pneumonia. Thorax 2004;59:421-7.

253. Johnstone J, Marrie TJ, Eurich DT, et al. Effect of pneumococcal vaccination in hospitalized adults with community-acquired pneumonia. Arch Intern Med 2007; $167: 1938-43$. 